University of Nebraska - Lincoln

DigitalCommons@University of Nebraska - Lincoln

2017

\title{
Linking Animals Aloft with the Terrestrial Landscape
}

Jeffrey J. Buler

Wylie C. Barrow Jr.

Matthew E. Boone

Deanna K. Dawson

Robert H. Diehl

See next page for additional authors

Follow this and additional works at: https://digitalcommons.unl.edu/usgsstaffpub

Part of the Geology Commons, Oceanography and Atmospheric Sciences and Meteorology Commons, Other Earth Sciences Commons, and the Other Environmental Sciences Commons

This Article is brought to you for free and open access by the US Geological Survey at DigitalCommons@University of Nebraska - Lincoln. It has been accepted for inclusion in USGS Staff -- Published Research by an authorized administrator of DigitalCommons@University of Nebraska - Lincoln. 


\section{Authors}

Jeffrey J. Buler, Wylie C. Barrow Jr., Matthew E. Boone, Deanna K. Dawson, Robert H. Diehl, Frank R. Moore, Lori A. Randall, Timothy D. Schreckengost, and Jaclyn A. Smolinsky 


\title{
Linking Animals Aloft with the Terrestrial Landscape
}

\author{
Jeffrey J. Buler, Wylie C. Barrow, Jr, Matthew E. Boone, \\ Deanna K. Dawson, Robert H. Diehl, Frank R. Moore, \\ Lori A. Randall, Timothy D. Schreckengost, \\ and Jaclyn A. Smolinsky
}

\begin{abstract}
Despite using the aerosphere for many facets of their life, most flying animals (i.e., birds, bats, some insects) are still bound to terrestrial habitats for resting, feeding, and reproduction. Comprehensive broad-scale observations by weather surveillance radars of animals as they leave terrestrial habitats for migration or feeding flights can be used to map their terrestrial distributions either as point locations (e.g., communal roosts) or as continuous surface layers (e.g., animal densities in habitats across a landscape). We discuss some of the technical challenges to reducing measurement biases related to how radars sample the aerosphere and the flight behavior of animals. We highlight a recently developed methodological approach that precisely and quantitatively links the horizontal spatial structure of birds aloft to their terrestrial distributions and provides novel insights into avian ecology and conservation across broad landscapes. Specifically, we present case studies that (1) elucidate how migrating birds contend with crossing ecological
\end{abstract}

J.J. Buler $(\varangle) \cdot$ M.E. Boone • T.D. Schreckengost • J.A. Smolinsky

Department of Entomology and Wildlife Ecology, University of Delaware, Newark, DE, USA e-mail: jbuler@udel.edu; boone@udel.edu; tschreck@udel.edu; jsmo@udel.edu

W.C. Barrow, Jr • L.A. Randall

U.S. Geological Survey, Wetland and Aquatic Research Center, Lafayette, LA, USA

e-mail: barroww@usgs.gov; randall1@usgs.gov

D.K. Dawson

U.S. Geological Survey, Patuxent Wildlife Research Center, Laurel, MD, USA

e-mail: ddawson@usgs.gov

R.H. Diehl

U.S. Geological Survey, Northern Rocky Mountain Science Center, Bozeman, MT, USA

e-mail: rhdiehl@usgs.gov

F.R. Moore

Department of Biological Sciences, University of Southern Mississippi, Hattiesburg, MS, USA

e-mail: frank.moore@usm.edu 
barriers and extreme weather events, (2) identify important stopover areas and habitat use patterns of birds along their migration routes, and (3) assess waterfowl response to wetland habitat management and restoration. These studies aid our understanding of how anthropogenic modification of the terrestrial landscape (e.g., urbanization, habitat management), natural geographic features, and weather (e.g., hurricanes) can affect the terrestrial distributions of flying animals.

\section{$1 \quad$ Using Weather Radar to Link Flying Animals Aloft with Terrestrial Habitats}

Despite using the aerosphere for many facets of their life, flying animals are still bound to terrestrial habitats for resting, feeding, and/or breeding. The alpine swift (Tachymarptis melba) exhibits perhaps the most extreme use of the aerosphere of any vertebrate by being able to remain airborne for 200 days while performing all vital physiological processes including sleeping (Liechti et al. 2013). However, it still returns to cliffs or caves to breed. Accordingly, the ecologies of animals in the air and on the ground coevolve and are inextricably linked. Terrestrial habitat quality, abundance, and distribution are of vital importance for maintaining species of flying animals. Additionally, terrestrial habitat plays an important role in shaping morphological, physiological, behavioral, and life history traits that impact the aerial ecology of flying animals. For example, habitat structure and selection are closely related to the wing morphology and the foraging and flight activity of birds (Robinson and Holmes 1982; Janes 1985; Winkler and Leisler 1985), bats (Brigham et al. 1997; Hodgkison et al. 2004), and insects (Hassell and Southwood 1978; Vandewoestijne and Van Dyck 2011). In turn, the aeroecology of flying animals shapes their terrestrial life histories and habitat use. For example, the improved dispersal capabilities of flying animals are shaped by global wind patterns and influence the evolution of migratory syndromes and pathways that expose animals to a changing suite of terrestrial habitats throughout the annual cycle (Able 1972; Gauthreaux 1980; Alerstam 1993; Moore et al. 1995; Drake and Gatehouse 1996; Gauthreaux et al. 2005; Dingle and Drake 2007; La Sorte et al. 2014a; Kranstauber et al. 2015).

Among available research tools for measuring the abundance of animals aloft, weather surveillance radars (WSR) offer the distinct advantage of being able to detect animal movements across broad spatial domains ( $100 \mathrm{~km}$ radius) at both a comparatively fine spatial resolution $(\sim 1-150$ ha) and at frequent intervals ( 4-10 min). Large networks of radars in the United States (Gauthreaux et al. 2003), Canada (Gagnon et al. 2011), and Europe (Shamoun-Baranes et al. 2014) provide opportunities for continental-scale monitoring of animal movements. Routine local movements of individual animals between aerial and terrestrial habitats are challenging to measure with WSR due to their closeness to the ground (typically within the atmospheric surface layer, i.e., $<100 \mathrm{~m}$ above ground level) and potential contamination from ground clutter. However, some animals initiate periodic 
and well-synchronized flights en masse that are comprehensively sampled by WSR in a way that can be used for rigorous scientific research. Recent radar-observed movements include seasonal migratory flights of insects (e.g., Westbrook et al. 2014) and birds (e.g., Buler and Dawson 2014), foraging flights of birds (e.g., Randall et al. 2011; Sieges et al. 2014), dispersal flights from communal roosts of birds (e.g., Laughlin et al. 2014) and bats (e.g., Frick et al. 2012), and twilight ascending flights by swifts (e.g., Dokter et al. 2013). WSR has provided novel information about population dynamics (see Chap. 15) and the phenology of annual life-cycle events (see Chap. 16) of flying animals that is not easily attainable by other means. WSR operating at low tilt angles can also provide information about where animals are concentrated or distributed in the terrestrial landscape by capturing patterns of flying animals as they enter the airspace en masse (Diehl and Larkin 2005, also see Chap. 12).

The nature of how various animals move and congregate gives rise to two main approaches for mapping their terrestrial distributions with WSR: (1) point mapping of roosts and other concentrations of animals and (2) continuous-surface mapping of animal distributions over broad geographic areas when initiating high-altitude synchronized flights. The two approaches differ in their consideration of when to sample animals aloft to accurately determine their on-ground locations and abundance and how to validate radar data with ground observations. We focus this chapter on discussing the application of these two approaches to mapping terrestrial distributions of animals with WSR. We highlight a recently developed methodological approach that precisely and quantitatively links the horizontal spatial structure of birds aloft to their ground distributions. We then present several case studies that improve our understanding of how anthropogenic modification of the terrestrial landscape (e.g., urbanization, habitat management), natural geographic features, and weather (e.g., hurricanes) can affect the terrestrial distributions of flying animals. We close by identifying some issues that present challenges for the use of WSR for mapping terrestrial distributions of flying animals and suggest areas for future research.

\section{$2 \quad$ Point Mapping of Terrestrial Concentrations of Flying Animals}

\subsection{The Mapping Process}

Roosts and some other animal concentrations are relatively easy to identify and locate in radar data. Animals taking flight from roosts often appear on radar as expanding rings or arcs emanating from a point source (Fig. 14.1) (Lack and Varley 1945; Elder 1957; Eastwood 1967). Roosting swallows, in particular, tend to leave the roost en masse, flying upward to high altitudes before turning out in nearly all directions, thus giving rise to these characteristic rings (Winkler 2006). Other manifestations of animal roosts can also be seen on WSR. Bats exiting roosts can take on a funnel shape, expanding outward as distance from the source increases 


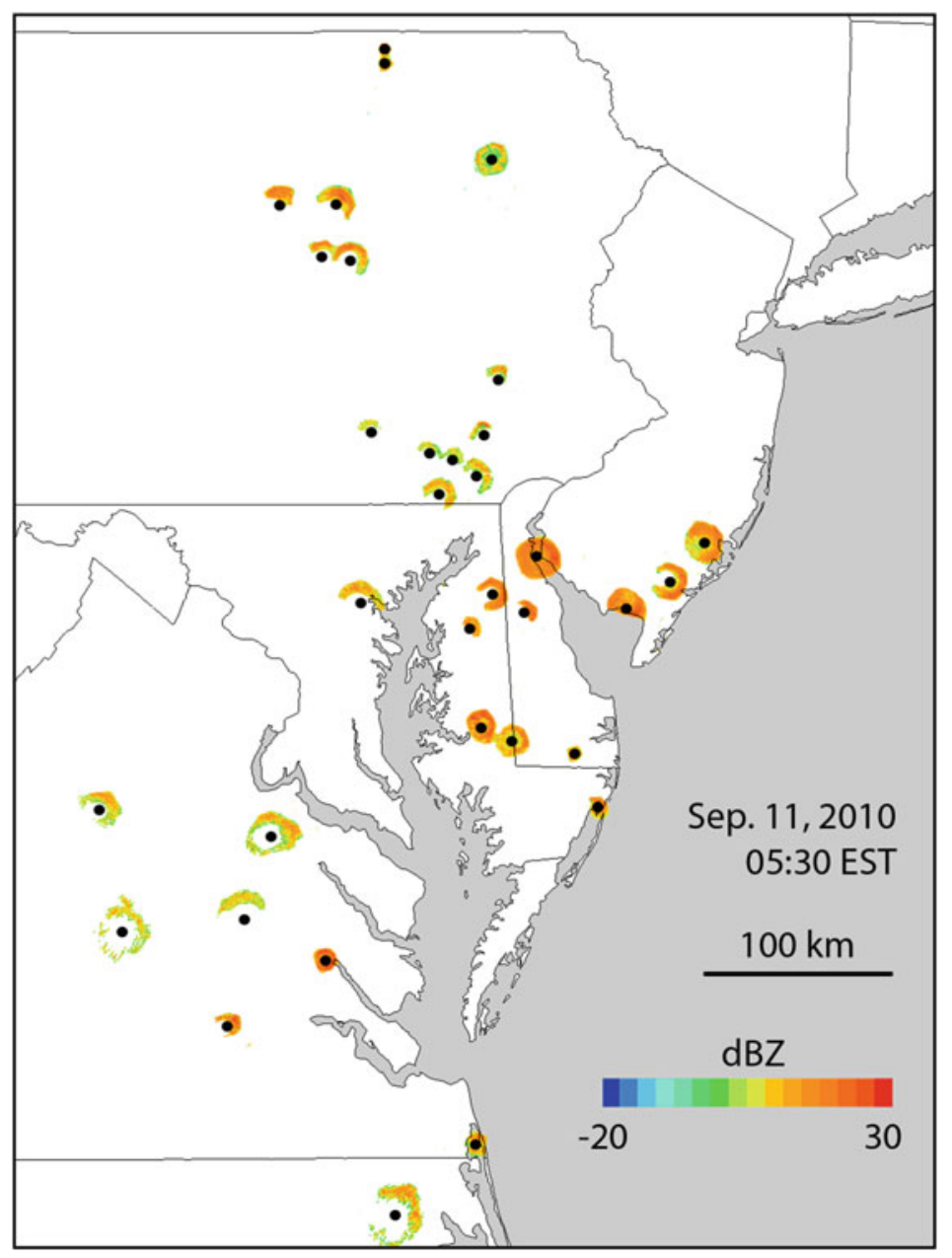

Fig. 14.1 Composite of radar reflectivity scans from 6 WSR-88D sites depicting the morning exodus flight of birds from 34 communal roosts on September 11, 2010, in the mid-Atlantic region of the United States. Black dots denote center of roost rings and presumed location of roosts. Reflectivity not attributed to bird roosts was removed for clarity

(Horn and Kunz 2008). Congregations of waterfowl leaving a discrete wetland site for migration appear as an irregularly shaped polygon growing laterally in size as they move away from the source (O’Neal et al. 2010).

These patterns allow roost locations to be easily pinpointed and mapped. Early radar studies typically involved visually analyzing "analog" photographs of radar scans to pinpoint locations of roosts. Modern approaches to pinpointing roost locations rely on georeferenced digital radar data and involve manually fitting a circle around a roost ring or arc within a geographic information system and calculating the geographic position of the circle center (Laughlin et al. 2013), or 
more-sophisticated automated image analysis algorithms such as patch identification (Horn and Kunz 2008) or a Hough transform (Larkin 2006) to recognize roosts and calculate their centers.

Pinpointing the location of roosts by observing animals as they enter roosts is sometimes difficult because of the disorganization and low altitude of aggregating flights. Large-bodied martins (Progne spp.) often fly low to the ground and under the radar beam or enter roosts as individuals or in small flocks over tens of minutes as sunset approaches (Russell and Gauthreaux 1998, 1999). By contrast, smaller swallows (Tachycineta bicolor, Stelgidopteryx spp.), as described by Winkler (2006), "congregate a few hundred meters above the roost site, milling around the site in an increasingly large and dense cloud of birds. Finally, as the last daylight fades, a few courageous birds make the plunge downward into the reeds of the roost site, followed immediately by a swirling stream of birds pouring into the vegetation, with hundreds of thousands of birds settling in only a few minutes' time." Other bird species may take as long as an hour or more to assemble at a location away from the ultimate roost location. For example, Eastwood et al. (1962) observed that roosting European starlings (Sturnus vulgaris) vary their pre-assembly location (up to a mile from the roost location) and time on a daily basis. The flock then moves from the pre-assembly location to the roost, occasionally circling the roost once or twice before entering and finally settling. This activity appears on the radar as a form of random variation in reflectivity or "effervescence" and can complicate pinpointing of the ultimate roost location.

Sampling expanding radar rings of animals aloft as they exit roosts does not require precise timing to accurately pinpoint roost locations. This is because expanding rings will typically appear on several radar scans in succession as animals expand out from their roost locations. This allows researchers either to select an individual scan from the series of scans depicting roost rings or to integrate information across the scans to pinpoint roost locations. For example, Laughlin et al. $(2013,2014)$ used the center of the circle in the first scan in which the roost was detected. Using a similar approach, Bridge et al. (2016) found that estimated locations of purple martin (Progne subis) roosts from radar images occurred within $10 \mathrm{~km}$ of actual ground-truthed locations. Moreover, some animals leave roosts in a succession of organized waves producing a sequence of expanding rings that appear much like the ripples in water after a tossed stone breaks the surface. Successive exodus waves increase the window of time for determining roost locations. For example, emerging waves of European starlings produce upward of 18 rings from the roost center at consistent average intervals of $3 \mathrm{~min}$, with complete evacuation of the roost taking at least $50 \mathrm{~min}$ (Eastwood et al. 1962). Brazilian free-tailed bats (Tadarida brasiliensis) at peak colony size typically exit roosts in 2-4 waves separated by 15-30 min intervals (Horn and Kunz 2008).

The temporal flexibility in sampling roost rings is important since the exact timing of roost exodus, especially for bats, can be quite variable. The evening exodus of bat colonies is one of the most easily and frequently studied aspects of bat behavior (reviewed by Jones and Rydell 1994). The timing of bat emergence appears to be primarily a function of diet and foraging strategy that balances 
predation risk and foraging time. Insectivorous bats that feed primarily on dipterans (i.e., the majority of temperate bat species) emerge relatively early during the peak flight activity of small insects about 20-40 min after sunset. However, emerging before dark exposes insectivorous bats to greater predation risk from raptors and possible competition from insectivorous birds. Bats that eat moths, flightless prey, or plants typically leave later at around 40-70 min after sunset, thus reducing predation risk (Jones and Rydell 1994). Roost exodus timing of bats also fluctuates daily and seasonally with weather and food availability. In dry seasons in central Texas when fewer insects likely exist, cave-dwelling bats emerged as early as $1.5 \mathrm{~h}$ before sunset, risking predation to increase foraging time (Frick et al. 2012). In contrast, during moist seasons bats emerged $30 \mathrm{~min}$ after sunset.

Variability in roost exodus timing is lower in birds than in bats. Russell and Gauthreaux (1999) found that the onset of roost exodus for purple martins across 32 days ranged from 31 to $48 \mathrm{~min}$ before sunrise, with flights lasting $68 \pm 12 \mathrm{~min}$ in duration. The fine-scale variability in the timing of exodus was related to atmospheric pressure and cloud cover, indicating that martins likely cued on daily fluctuations in ambient light intensity when departing roosts (Harper 1959; Russell and Gauthreaux 1999).

Complete rings are usually observed only when animals disperse away in all directions at a consistent speed under no or light winds $(<3 \mathrm{~m} / \mathrm{s})$. Under these conditions, the center of a ring remains stationary over the roost location until exodus flight is completed (Ligda 1958; Eastwood 1967). However, displacement of complete rings downwind is sometimes observed under stronger winds $(3-6 \mathrm{~m} / \mathrm{s})$ without drift correction by animals (Eastwood 1967; Russell and Gauthreaux 1999). With yet further increase in wind speed, radars observe arcs of animals that move downwind, as opposed to complete rings. In these cases, arc formations are not caused by an absence of animals in the upwind direction but rather from a tendency for animals to fly into the wind at a lower altitude and thus remain undetected by the radar. However, arcs may also be seen when animals show directionality in their movement. For example, arcs are observed for some bird roosts located near water bodies, since landbirds may avoid dispersing over water (Eastwood 1967). Arcs are also observed when birds leave roosts to embark on directed migratory flights (Harper 1959; Russell and Gauthreaux 1999). Horn and Kunz (2008) found that surface winds do not appear to affect the initial direction or the speed at which Brazilian free-tailed bats set out to forage. Rather, bats show directed flight toward masses of emerging, dispersing, or migrating insects (Cleveland et al. 2006). In situations where drifting rings or arcs are seen, a correction for wind velocity can be applied (e.g., Eastwood et al. 1962) or the trajectory of the arc can be traced back to its origin with an object-tracking algorithm (e.g., Horn and Kunz 2008). In other studies, no correction is made for potential drifting of roost rings or arcs (e.g., Russell et al. 1998; Laughlin et al. 2013).

Identifying the species composition of animal roosts that appear on radar is easily confirmed on the ground by placing observers at the center of the expanding rings or arcs as animals leave roosts (e.g., Eastwood et al. 1962) or by matching the center location of radar rings with already known roosts (e.g., Kelly et al. 2012). 
Alternatively, in one of the first studies to document observations of bat roosts on radar, Williams et al. (1973) confirmed by helicopter that the reflectivity on airport surveillance radars in Texas was caused by groups of Brazilian free-tailed bats dispersing from caves to forage. O'Neal et al. (2010) used other remote-sensing tools to identify the coarse taxonomic identity of individual waterfowl emanating from a discrete wetland complex in Illinois for nocturnal migratory flight-a thermal infrared camera to record animal shape and a portable stationary-beam $\mathrm{X}$-band radar to measure wing beat frequencies. The time of day or season when roost rings appear on radar can also be used as a clue to the identity of animals producing them. For example, purple martins roost communally from the end of their breeding season until they depart for tropical wintering areas in late July and August, while roosts of species that winter in temperate regions (e.g., tree swallow, red-winged blackbird) are used for much longer (Winkler 2006). Foraging bats and foraging or migrating waterfowl leave diurnal roosts in the evenings after sunset, while diurnally active birds generally leave nocturnal roosts shortly before sunrise.

\subsection{Ecological Insights}

Communal roosting is often a regional phenomenon that involves broad spatial and temporal relationships among roosts (Caccamise et al. 1983). However, early radar studies of spatial and temporal dynamics of roosts were limited in scope to providing "local"-scale information (e.g., Ligda 1958; Harper 1959; Eastwood et al. 1962). For example, Eastwood et al. (1962) used a single radar in England to study the dynamics of European starling roost locations over the course of 2 years. The lack of any distinctive topographic features in the landscape associated with persistent ring centers led the researchers to suspect starlings as the source of the rings, which was confirmed by observers on the ground. By monitoring roost activity over time, they were able to determine there were upward of 12 persistent roosts of resident starlings and several temporary roosts of migrating starlings. Of particular note was a large persistent roost that was detectable within the center of Trafalgar Square in London despite clutter radar echoes produced from surrounding tall buildings. Eastwood et al. (1962) documented changes in the locations of starling roosts in response to anthropogenic disturbance. For example, one roost location changed after local farmers shot many individual starlings.

Most roost mapping studies in the United States have been conducted since the establishment of the network of more than 150 WSR-88D stations and digital archiving of radar data in the mid-1990s. The archived observations from these networked radars have allowed for examination of roost location dynamics at a sufficiently large scale to detect regional and seasonal patterns over many years, which wasn't possible in earlier radar studies.

\subsubsection{Bat Roosting Ecology}

The first observations of bat colonies on WSR-88D were made in Oklahoma and Texas soon after the installation of the network (Ruthi 1994; McCracken and 
Westbrook 2002). By studying the dynamics and locations of maternity colonies of Brazilian free-tailed bats for 11 years around a WSR-88D station in Texas, Horn and Kunz (2008) provided new insight into bat roost dynamics. They found that bats occupy bridge roosts more frequently than cave roosts early in the spring and late in the fall despite the potential negative aspects of noise, air pollution, and disturbance from humans. Concrete bridges with expansion joints may offer a significant thermal advantage over caves during the cooler periods of the roosting season by having warmer and more stable temperatures. Additionally, they hypothesized that occupancy of bridges may relieve overcrowding in the limited number of suitable roosting spaces in caves.

\subsubsection{Bird Roosting Ecology}

The first large-scale mapping of purple martin roosts in the United States, using 45 networked WSR-88D stations across 19 states, was conducted by Russell et al. (1998). Roost sites were consistently detected if they were within $100 \mathrm{~km}$ of a radar and occasionally up to $240 \mathrm{~km}$ from a radar, likely when the radar beam was being strongly refracted. More recent studies use $175 \mathrm{~km}$ as a threshold distance for detecting large swallow (Hirundinidae) roosts (Kelly et al. 2012; Laughlin et al. 2013). The detection range is limited in part by "range" bias (sensu Diehl and Larkin 2005), which is caused by the increasing height of the radar beam above the ground as it travels away from the radar. Orographic terrain relief can also impact the range coverage of a radar and, thus, detecting roosts. Radar detection of animals leaving roosts is also limited by their flight heights. For example, Russell and Gauthreaux (1998) found that WSR-88D detected 80\% of roost departures observed during ground surveys at a purple martin roost located $28 \mathrm{~km}$ from the radar. Roost exodus went undetected when rain obscured radar detection of birds ( 2 days), birds flew just above the treetops because of fog or low cloud ceiling (4 days), or the radar beam experienced extreme sub-refraction and passed above the birds (2 days).

The Russell et al. (1998) and Russell and Gauthreaux (1998) studies provided a proof of concept that bird roosts over a large geographic area could be mapped easily with minimal resources using the radar network. Most of the 33 identified roosts were associated with areas of open water. Subsequently, more extensive identification and ground validation of radar-observed roost locations, conducted by volunteers of the Purple Martin Conservation Association, have documented 358 suspected martin roost sites within eastern North America (www.purplemartin. org/research/19/project-martinroost/). Furthermore, the comprehensive study by Bridge et al. (2016) evaluated habitat associations and persistence of 234 purple martin roosts over most of their range. They found that martins actually use a diverse array of roosting habitats including forest, cropland, and urban development in addition to areas adjacent to open water. Moreover, martins appear to prefer urban sites, and urban roosts were associated with the high year-to-year persistence.

Kelly et al. (2012) developed an approach that extends the use of WSR beyond simple mapping of roost locations to automated monitoring of the phenology of roost activity and relative sizes of the 358 roosts identified by the Purple Martin Conservation Association. They used the daily maximum radar reflectivity value 
recorded within the hour before sunrise within a $9-\mathrm{km}^{2}$ grid centered at each roost location as an index of the number of individuals within a roost (i.e., roost size). They found that roosts farther away from a radar station do not appear as consistently as those closer in and that roost size was negatively related to distance from the radar. Furthermore, Laughlin et al. (2014) found that variability in precision of swallow roost locations was positively related to distance from the radar. These studies highlight that range bias in detection, location, and size estimation of roosts remains a challenge that needs to be addressed for future quantitative studies, especially for those that seek to directly compare point locations across the radar domain.

Phenology of roosts has provided insight into the stopover and overwintering habitat use of tree swallows (Tachycineta bicolor) too. Laughlin et al. (2013) integrated WSR-88D observations with telemetry of individually marked birds to study stopover habitat use in southeastern Louisiana by several breeding populations of tree swallows from across North America. Numbers of tree swallows in sugarcane roosts decreased as harvest of sugarcane commenced. Large roosts of $>1$ million birds decreased to the tens of thousands near the end of harvest. It appears that the sugarcane fields are used as autumn stopover habitat for swallows, and wetland areas are used as overwintering habitat for the few birds that remain. More recently, Laughlin et al. (2016) found strong correlations between radarestimated and eBird-estimated occupancy dynamics of tree swallow roosts. The long-term occupancy dynamics based on radar data provided evidence that Louisiana acts as a combined stopover and overwintering region, whereas Florida occupancy dynamics were akin to a traditional winter region.

Radar observations have revealed that over much of their migratory and wintering ranges, swallow roost sites in general appear to have fairly consistent spacing (Winkler 2006). Roost sites in eastern North America tend to be about 100-150 km apart. Based on these observations, Winkler (2006) proposed a series of testable questions about swallow migration strategies and roost-site dynamics. For example, given that roost spacing is within the range of a day's flight, he hypothesized that birds migrating through the day could easily reach the next roost site in the successive chain of nocturnal roosts. He predicted the mechanism for individuals to find roosts along the chain could be for experienced birds to recall a navigational map of previously used sites (i.e., roost fidelity) and/or for individuals to simply forage in the preferred migratory direction and then be recruited to the next roost by aggregating near the end of the day with other birds that used that roost the previous night (i.e., conspecific attraction). Understanding the mechanisms of roost selection could illuminate why certain sites are consistently used from year to year while others are more ephemeral in nature. These mechanisms may also inform the causes of the intra- and interannual changes in roost sizes.

In a related study, Laughlin et al. (2014) examined tree swallow roost dynamics during fall migration. They observed roosts forming in the same places each night, which indicated a fairly high level of individual roost fidelity. However, radiomarked individuals switched between roosts at a rate of at least $22 \%$ each night and showed some attraction to conspecifics going toward other roosts. Thus, the pattern 
of tree swallow roosting dynamics seems largely explained by individuals exhibiting a combination of moderately high roost-site fidelity coupled with moderate conspecific attraction.

\subsubsection{Stopover Ecology of Waterfowl Congregations}

O'Neal et al. (2010) developed a rigorous approach to use WSR to identify and enumerate the ducks emigrating from a 12,000 ha wetland stopover complex in central Illinois over the course of a fall migration season. This approach entailed determining an average radar cross section for an individual duck and summing the total reflectivity of the discrete patch of reflectivity (i.e., flock of birds) emanating from the wetland complex on a nightly basis. The system was unique in that the reflectivity of the emanating flock of birds did not mix with reflectivity from other sources and could be confidently attributed to the "point" ground source.

In a subsequent study, O'Neal et al. (2012) used WSR data in combination with data from weekly aerial censuses to estimate an average seasonal stopover duration for fall-migrating dabbling ducks across eight seasons. Their rather elegantly simple approach entailed dividing the total numbers of emigrants leaving the complex over the course of a migration season by the total duck-use days for the season determined via the aerial surveys. The quotient of the two measures provides an estimate of stopover duration in units of days. The mean seasonal stopover duration was 28 days (range 11-48 days), which is identical to a 28-day estimate for mallards (Bellrose and Crompton 1970) and consistent with a 21-day estimate for all dabbling duck species (Bellrose et al. 1979). Furthermore, O'Neal et al. (2012) found a positive relationship between seasonal stopover duration with a seasonal index of foraging habitat quality. Thus, migrating ducks appear to assess local stopover site conditions and adjust the amount of time they stop over accordingly. The wide flexibility in stopover duration that they observed is consistent with the hypothesis that ducks allocate their time adaptively among individual stopovers (Harper 1982), although the extent to which this flexibility reflects interindividual adaptation (e.g., Harper 1982) or adaptive stopover (e.g., Weber et al. 1999; Beekman et al. 2002; McLaren et al. 2013) is untested.

\section{Continuous-Surface Mapping of Terrestrial Distributions of Broadly Dispersed Animals}

The advent of digital measurement and recording of radar reflectivity by WSR networks in the United States (Crum et al. 1993) and Europe (Holleman et al. 2008) allows for more quantitative treatment of reflectivity and, combined with modern geographic information systems, the ability to summarize and map continuous surfaces of bioscatter over space and time within radar domains (Gauthreaux et al. 2003). Surface mapping of the terrestrial distributions of flying animals with WSR is a technically challenging and novel application that requires animals to be sampled immediately upon entering the radar-swept airspace before they have dispersed far from their ground sources (Diehl and Larkin 2005). Because animals 
of interest typically are much closer to the ground than the precipitation that the WSR networks were designed to sample, there are often large gaps in the network where flying animals cannot be detected (Fig. 14.2). Thus, unlike precipitation data, WSR networks don't provide comprehensive continuous coverage of bioscatter across the entire network. In fact, Buler and Dawson (2014) estimated that only about one-third of the land area in the northeastern United States is robustly sampled by WSR for surface mapping of animal distributions. To date, continuous surface mapping has only been conducted using the United States' WSR-88D network to sample bird distributions at the onset of nocturnal migratory flights (e.g., Bonter et al. 2009; Buler and Moore 2011; Ruth et al. 2012; Buler and Dawson 2014) and nocturnal feeding

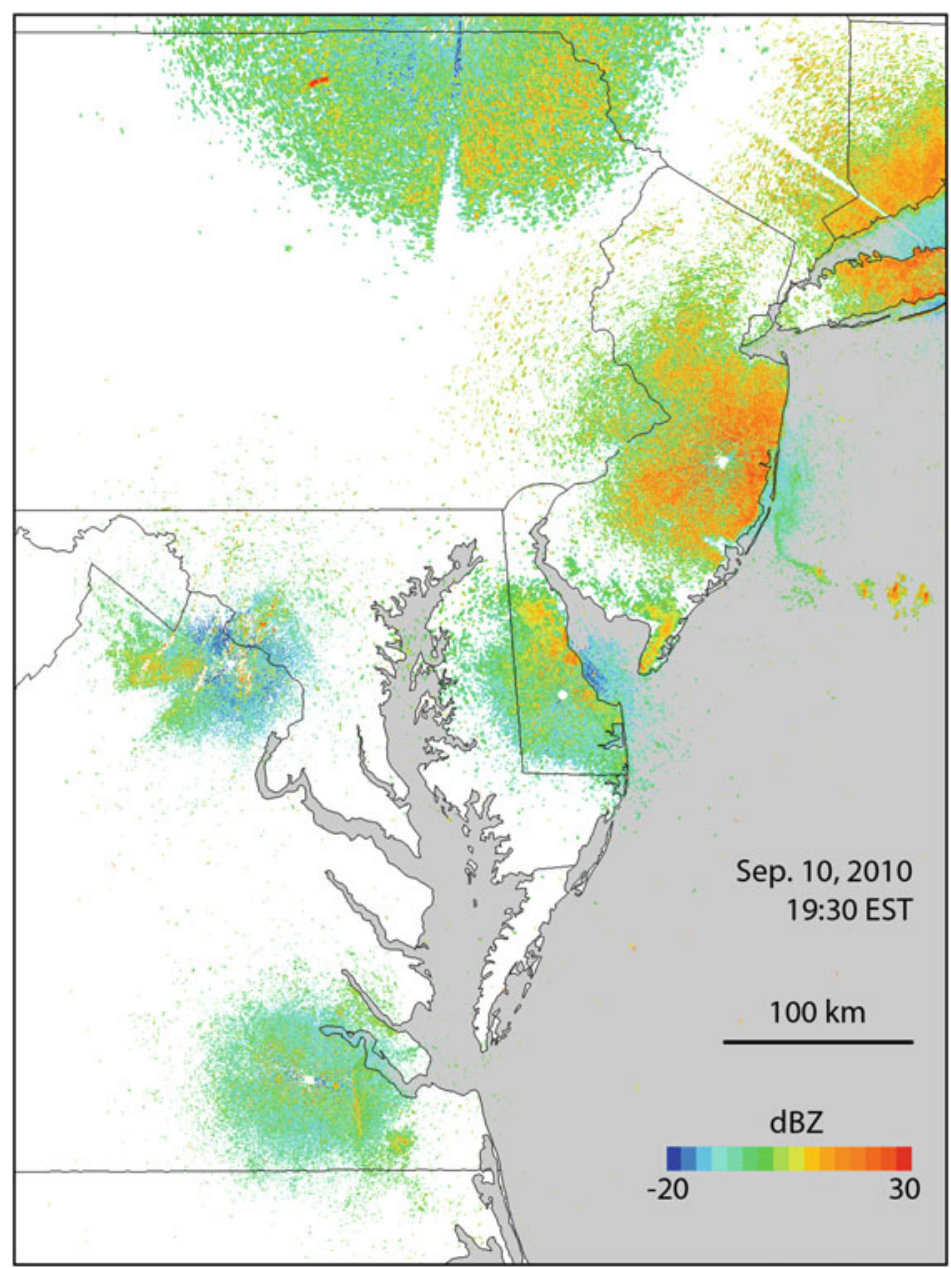

Fig. 14.2 Composite of radar reflectivity scans from 6 WSR-88D sites depicting the evening onset of migratory flights of birds on September 10, 2010, in the mid-Atlantic region of the United States. Areas of greater reflectivity (dBZ) coincide with areas of greater bird density 
flights of waterfowl (e.g., Buler et al. 2012b; Sieges et al. 2014). The remainder of this chapter will therefore focus on continuous-surface mapping of bird distributions. However, most aspects of mapping bird distributions are applicable to mapping terrestrial distributions of other flying animals. Mapping ground distributions of emerging migrating insects or bats may be possible when either taxa is dominant within the airspace, but such attempts have not yet been made.

\subsection{The Mapping Process}

Sampling terrestrial distributions of birds with WSR is generally done with a single near-instantaneous radar scan for a given night at the lowest elevation sweep as birds leave their terrestrial habitats near the initial onset of well-synchronized en masse flights (Buler and Diehl 2009). This approach helps to preserve the geographic fidelity and structure in animal distributions (Buler et al. 2012b). Widely distributed birds appear as sudden "blooms" of reflectivity centered around radars as they take flight and enter radar-sampled airspace (Fig. 14.2). At an early stage of the onset of flight, bird reflectivity measures throughout the radar domain can vary by orders of magnitude, with greater values coinciding with habitats that contained more birds. Within minutes, as the initial birds continue to gain altitude and disperse away from their point of departure, the bloom of reflectivity expands and reflectivity measures become more homogeneous. Migrating landbirds and foraging flights of waterfowl continue to emerge from terrestrial habitats for at least $30 \mathrm{~min}$ (Hebrard 1971; Åkesson et al. 1996; Buler et al. 2012b; Wingo and Knupp 2014). Gauthreaux and Belser (2003) used multiple radar scans over a time period of 20-50 min during the onset of bird migration on a given night to map generalized stopover areas of high relative bird density. In contrast, continuous-surface mapping requires more precise timing for the selection of a single radar scan. How the accuracy and precision of radar data for mapping ground distributions decline through time has not been empirically evaluated for migrating landbirds, but for feeding flights of waterfowl, it appears to peak about $10 \mathrm{~min}$ after the initiation of flight (Buler et al. 2012b).

As with point mapping, continuous-surface mapping by sampling birds aloft as they descend into terrestrial habitats may be nearly impossible because the descent is generally not synchronized. Gauthreaux (1971) described the behavior of small flocks of migrating landbirds as they arrived on the northern coast of the Gulf of Mexico following an 18-24 h over-water flight. He wrote that "as a flock high aloft moved over a coastal woodland some of the individuals hesitated, hovered, or flew in broad, shallow spirals while the remaining flock members continued farther inland. The individuals that left the flock then closed their wings and dove nearly straight down." From a radar perspective, birds that remain aloft would continue to produce radar echoes and largely obscure the activity of individual birds making landfall. The radar echoes disappear only when the last birds descend into terrestrial habitats. Subsequently, in the only published study to examine landfall patterns, Gauthreaux (1975) observed that migrating birds disappeared from radar scans at forests $46-140 \mathrm{~km}$ inland from the coastline even when flying into adverse weather. 
His study helped explain the scarcity of migratory birds within the coastal plain of Louisiana (i.e., coastal hiatus; Lowery 1945). Additionally, flocks of wintering waterfowl have been anecdotally observed to terminate their nocturnal feeding flights at flooded rice fields in the Central Valley of California (Buler et al. 2012b). However, only limited qualitative inferences can be made about terrestrial habitat use based on monitoring the termination of bird flights on radar.

More generally, there are several sources of measurement bias related to how radars sample the air and the flight behavior of animals that should be addressed to maximize accuracy in mapping animal density on the ground (Diehl and Larkin 2005). We highlight recently developed and increasingly sophisticated methodological approaches that minimize several of these biases and other data quality control issues to produce continuous-surface maps (Fig. 14.3) that precisely and quantitatively link the horizontal spatial structure of birds aloft to their terrestrial distributions.

\subsubsection{Range Bias}

Perhaps the biggest source of measurement bias is caused by the increase in altitude of the radar beam above the earth's surface with increasing range from the radar (Fig. 14.4). This leads to a systematic decline in reflectivity values with increasing range when sampling animals close to the ground. This range bias precludes direct comparison of raw reflectivity measures across ranges. Furthermore, the bottom of the radar beam eventually passes completely over animals in the airspace (i.e., beam overshoot) and will record no reflectivity even when animals are present in the airspace. Although dependent on the heights of animals in the air, the refractive conditions of the atmosphere, and the elevation angle of the radar beam, beam overshoot from WSR-88D occurs on average at $\sim 80 \mathrm{~km}$ from the radar when sampling birds at exodus in relatively flat terrain at the lowest elevation angle (Buler and Diehl 2009; Buler et al. 2012b). The very narrow beam at ranges closest to the radar combined with relatively sparse densities of animals aloft creates greater uncertainty in reflectivity measures that justify filtering data close to the radar (Chilson et al. 2012).

In the absence of range bias correction, researchers generally limit comparisons of terrestrial habitat use to a subset of data at similar ranges. For example, Bonter et al. (2009) compared a few selected locations of high bird density paired with areas of low density at the same distance from the radar to characterize land covers and landscape contexts corresponding to high-use areas by migrating landbirds in the Great Lakes region. Thus, they effectively reduced continuous-surface data into coarse point location data (i.e., 5-km radius areas). However, they acknowledged they were unable to analyze radar data at a finer scale, which is key for informing conservation efforts on a site-by-site basis. As an alternative approach to limit the effect of range bias, Ruth et al. (2012) maintained continuous-surface data but restricted their analysis of land cover and migrant stopover density in the southwestern United States to a $15-\mathrm{km}$ band ranging from 35 to $50 \mathrm{~km}$ away from a radar. While this restriction was severe, they were still able to document differences in bird densities among a variety of land cover types by analyzing data from several radars. 


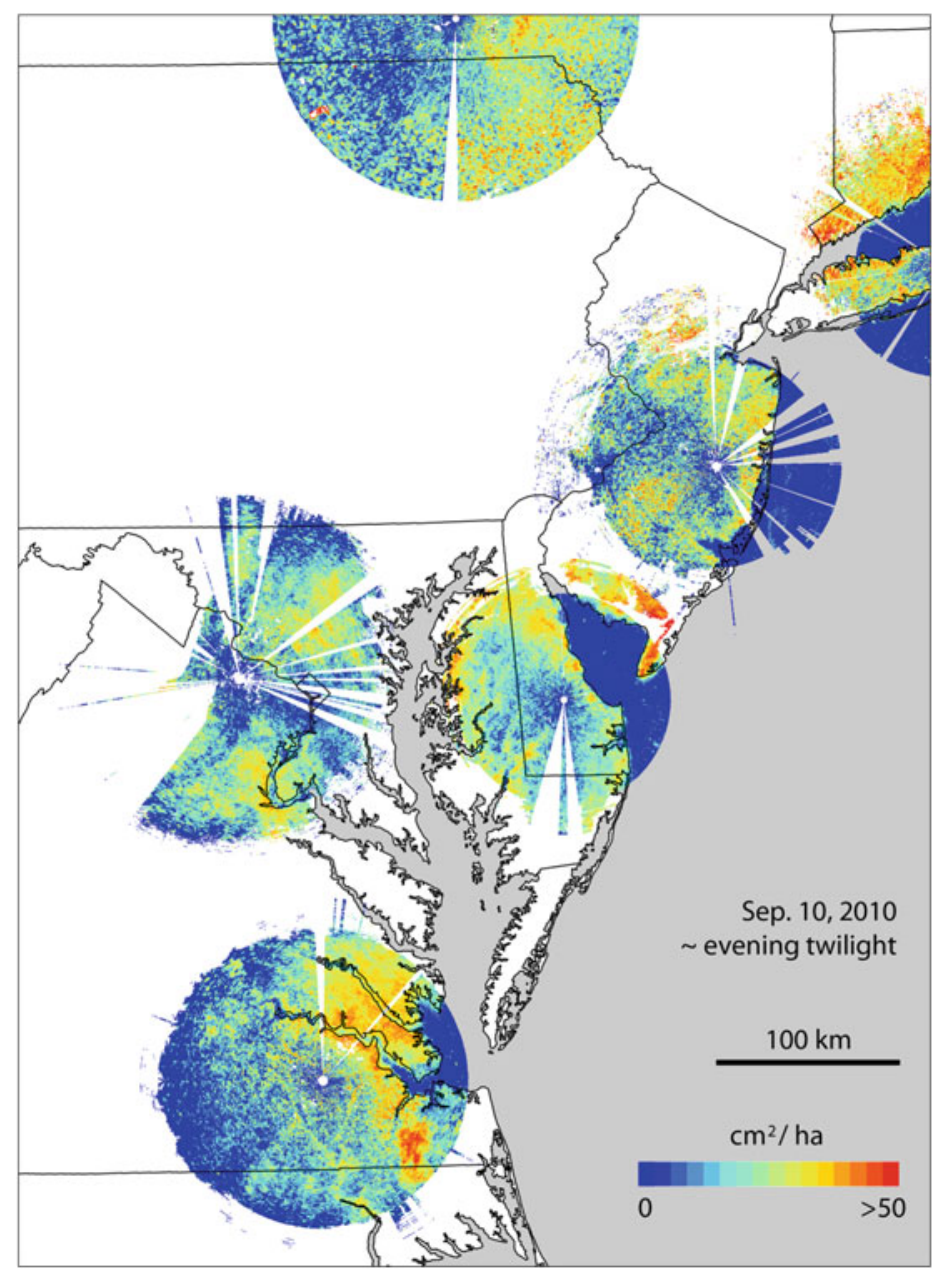

Fig. 14.3 Composite of bias-adjusted vertically integrated reflectivity scans from 6 WSR-88D sites depicting the evening onset of migratory flights of birds on September 10, 2010, in the mid-Atlantic region of the United States following Buler and Dawson (2014). Areas of greater reflectivity $\left(\mathrm{cm}^{2} / \mathrm{ha}\right)$ coincide with areas of greater bird density

Range bias can be minimized by adjusting radar reflectivity measures from individual radar sample volumes (the basic radar sampling unit, measuring $250 \mathrm{~m}$ in range by $0.5^{\circ}$ in diameter) into equivalent reflectivity measures with respect to a common height reference across all sample volumes [i.e., vertically integrated reflectivity (VIR)]. Essentially two pieces of information are needed for this: the height limits of the radar beam for every sample volume and the mean vertical profile of reflectivity (VPR) of animals aloft at the time of sampling. Established methods for determining radar beam limits include estimating where the beam is 


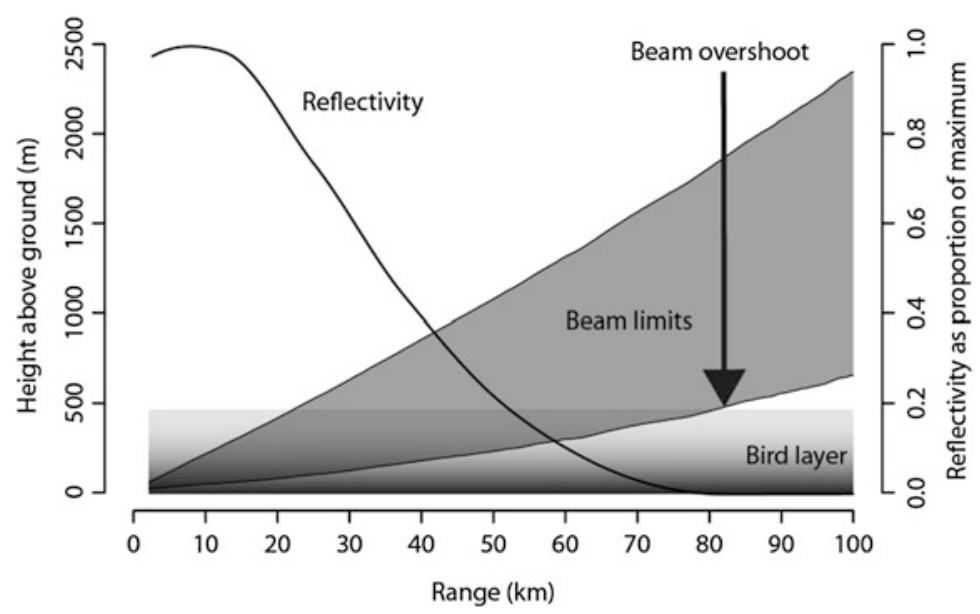

Fig. 14.4 Example illustration of declining radar reflectivity with increasing range measured within the limits of a $3-\mathrm{dB}$ radar beam propagating in a standard atmosphere at $0.5^{\circ}$ elevation (gray region bounded by narrow black lines) for a homogeneous layer of birds across ranges. The bird layer extends from the ground to $500 \mathrm{~m}$ above ground and is presented as the gradient-filled box to depict increasing bird density closer to the ground. The radar beam completely overshoots the bird layer starting at around $82 \mathrm{~km}$ range, which coincides with measured reflectivity of zero despite birds in the air

blocked by topography using digital elevation models (Bech et al. 2003) and modeling beam propagation paths assuming a standard atmosphere (i.e., simple) or using a piecewise linear model of the refractive-index gradient constructed from ancillary radiosonde observations (i.e., complex) (Doviak and Zrnic 1993). The VPR is a function that describes the ratio of the reflectivity at a given height interval with respect to a reference, generally the average reflectivity from the ground to the highest beam height considered. Buler and Diehl (2009) developed an algorithm to derive a high-resolution (i.e., at 10-m height intervals) mean apparent VPR by integrating radar data from the five lowest elevation angle sweeps near the radar. The quotient of the observed reflectivity and the beam-area-weighted mean VPR ratio sampled within a given sample volume gives the estimated VIR that can be compared directly across the radar domain. VIR in volumetric units of $\mathrm{cm}^{2}$ per $\mathrm{km}^{3}$ can be "flattened" to the ground by multiplying it by the reference height range measured in kilometers to derive a surface bioscatter estimate in units of $\mathrm{cm}^{2}$ per $\mathrm{km}^{2}$. The accuracy of VIR estimates relies on developing fine resolution beam propagation models and VPRs since animals occupy only a few hundred meters of airspace when sampled near the onset of flight. For example, using a high-resolution refractive index from radiosonde observations to model beam propagation can help improve the correlation between the VIR of birds aloft and their ground densities (Buler and Diehl 2009).

Range bias also gives rise to the need for considering effective detection range and deciding how to censor unreliable radar data. Unfortunately, the effective 
detection range of the radar is highly dynamic within and among radar scans due to variability in local topography, the vertical distribution of animals aloft, atmospheric refraction of the radar beam, and attenuation of the radar signal, which can impact the minimal detectable density of birds. Thresholds can be set to censor data based on the extent of beam overshoot or the magnitude of the VPR-based adjustment factor (e.g., where the radar beam passes over $90 \%$ of birds in the airspace or there is a $>20$-fold increase in observed reflectivity; Buler and Dawson 2014). The variable detection limits also create a scenario of multiply censored data that can introduce error when deriving summary statistics among radar scans. This error has been minimized (e.g., Buler et al. 2012b; Buler and Dawson 2014) by using the semiparametric robust linear regression on order statistics (ROS) method for estimating summary statistics of multiply censored data (Lee and Helsel 2005).

\subsubsection{Ground Clutter and Beam Blockage}

Areas of persistent ground clutter contamination or partial radar beam blockage from human infrastructure or topography need to be identified to avoid mistaking strong clutter echoes as flying animals or blocked areas as being devoid of animals. These masking maps are an important component of data quality control and are easily created by summarizing the detection probabilities of reflectivity from thousands of scans over long time periods (Kucera et al. 2004). Masking maps help augment the inherent dynamic clutter suppression algorithms of WSR as well. Partial beam blockage from topographic relief can also be modeled (Bech et al. 2003). Radars in areas of wide relief may have extensive beam blockage, which can reduce the efficacy of some radars for mapping terrestrial distributions of flying animals. Moreover, these radars may also be prone to violating assumptions of homogeneous VPRs throughout the radar domain and, consequently, "overcorrection" of range bias algorithms and thus may warrant special considerations (e.g., Ruth et al. 2012).

\subsubsection{Sun Angle Bias and Exodus Timing}

En masse initiations of animal flight are often closely synchronized to the elevation of the sun. These include migratory flights of landbirds (Gauthreaux 1971; Hebrard 1971; Åkesson et al. 1996), waterfowl (O’Neal et al. 2010), and insects (Westbrook 2008; Westbrook et al. 2014) and feeding flights of wintering waterfowl (Raveling et al. 1972; Baldassarre and Bolen 1984; Ely 1992; Cox and Afton 1996; Randall et al. 2011; Buler et al. 2012b). Many of these flights occur under the cover of darkness and begin shortly after sunset near the end of civil twilight when atmospheric conditions are stable, multiple environmental cues are optimally available for flying animals, and visual predators are thwarted. For example, the magnitude and variability in horizontal and vertical winds reach their minimum about $20 \mathrm{~min}$ after sunset (Wingo and Knupp 2014). Additionally, important navigational cues from the sun's position on the horizon, skylight polarization, and astronomical cues are only all available at the end of civil twilight (Kerlinger and Moore 1989; Åkesson et al. 1996). In particular, the skylight polarization pattern during twilight is stable, intense, and closely aligned along the north-south axis (Cronin et al. 2006), which provides important directional information for migrating birds 
(Moore and Phillips 1988; Able 1989; Helbig and Wiltschko 1989; Helbig 1990; Muheim et al. 2007; Muheim 2011).

Mapping terrestrial distributions of birds among multiple radars typically involves careful selection of individual radar scans at similar sun angles or timing in relation to the onset of migration (Bonter et al. 2009; Buler and Moore 2011; Ruth et al. 2012). However, small differences among radars in the exact sampling timing of radar scans with respect to relative sun angle can introduce bias in reflectivity measures (Buler and Diehl 2009). These small differences in timing can arise due to the lack of synchronization of radars to the onset of bird flights and the relatively coarse sampling rate of WSR-88D (i.e., one scan per 4-10 min) during the sudden onset of bird flight when the number of birds aloft can double every few minutes (Hebrard 1971; Åkesson et al. 1996). Furthermore, there is about an 8-min time differential in sun elevation along an east-west axis across the radar domain at mid-latitudes. Thus, there is potential for significant sun angle bias even within a single radar domain.

As an example, we measured the onset of autumn nocturnal migration flight of birds at the KLIX radar in Slidell, Louisiana, USA, during 13 nights. We divided the radar domain within $50-60 \mathrm{~km}$ of the radar into 18 7-km-wide longitudinal bands. For each night, we fit a logistic growth curve within each band through the mean reflectivities from a series of radar scans during the onset of migration (Fig. 14.5) and extracted the time of the inflection point of the "exodus" curve. We then used the slope of the linear regression between inflection point time (dependent variable) and longitude (independent variable) to derive the speed at which the inflection point of exodus curves moves to the west for each night. The mean observed speed of inflection points of flight exodus curves $(21.2 \pm 4.7 \mathrm{~km} /$ min) was not different $(T=-1.76, d f=12, P=0.9)$ from that of the predicted speed of the sunset terminator $(23.6 \mathrm{~km} / \mathrm{min})$.
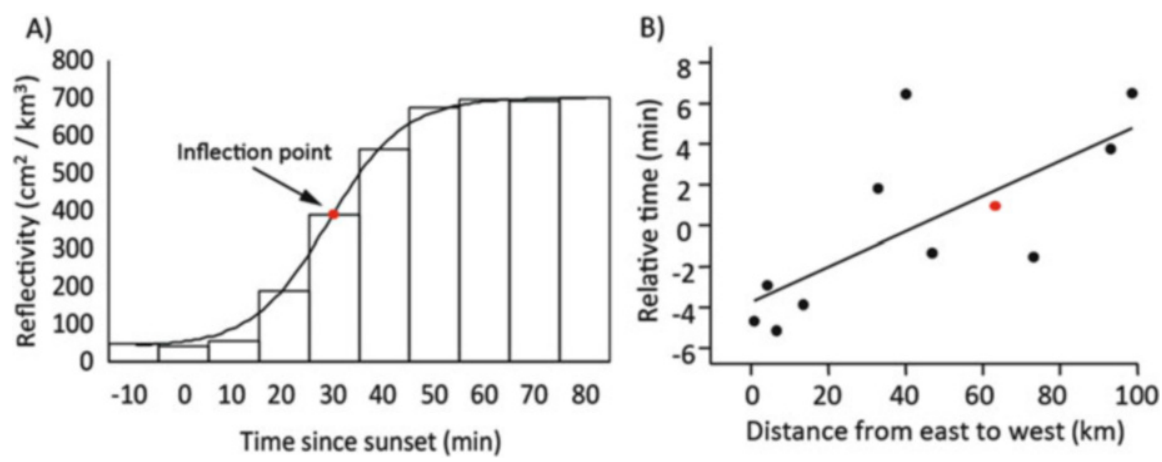

Fig. 14.5 (a) Example "exodus curve" at the onset of bird migration within a single 7-km wide longitude band to derive the inflection point of peak change in mean reflectivity (red dot) among radar scans (bars). (b) This inflection point was combined with similarly derived inflection points from other longitude bins within the same radar domain (black dots) in a linear regression model to determine the speed of the onset of migration for a given night 
Approaches have been developed to reduce sun angle bias both within and among radars. These approaches involve interpolating reflectivity measures to a static relative time point with respect to sun elevation at every sample volume across all sampling nights and radars (Buler et al. 2012b; Buler and Dawson 2014). However, using a static sun angle for all nights and radars may still introduce bias because there is variability in the onset of flights between nights within and among radars. For example, Gauthreaux (1971) found a 15-min range in timing of the onset of nocturnal bird migration across nights relative to sunset at a single radar. Thus, a new approach further reduces sun angle bias; it dynamically samples at the sun angle at the peak rate of change in reflectivity during exodus (i.e., when the greatest numbers of birds depart) for each night and radar (McLaren et al. 2018).

Visual observations and radio telemetry of individual birds show that peak exodus times occur close to those observed by nearby radar (Gauthreaux 1971; Hebrard 1971; Åkesson et al. 1996). However, mean peak exodus was earlier on radar compared to that of radio-marked Swainson's thrushes (Catharus ustulatus) using data from two separate studies with overlapping study areas in coastal Alabama, USA (Fig. 14.6). While exhibiting similar duration of flight exodus, results from Smolinsky et al. (2013) indicate that the peak exodus time of migrating thrushes in autumn ( sun angle $=-9.0^{\circ}$ ) was about 9 min after the mean peak exodus time of bird-dominated flights on the nearby Mobile, Alabama radar (sun angle $=-7.0^{\circ}$; Buler and Moore 2011). Others have found that departures of the earliest cohort of Swainson's thrush are also largely restricted to the period of

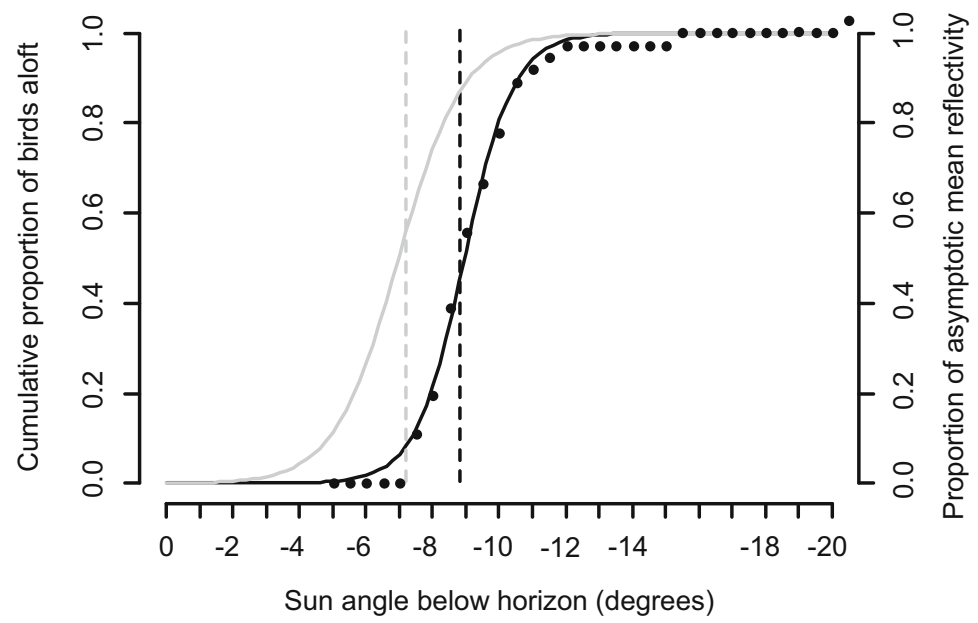

Fig. 14.6 Modeled logistic growth curves relative to sun angle depicting (1) the cumulative portion of 37 radio-marked Swainson's thrushes (black dots) aloft at the onset of nocturnal flights during autumn migration at Fort Morgan, Alabama 2008 and 2009 (black line), and (2) the increase in mean reflectivity among 12 autumn nights during 2002 and 2003 around the KMOB (Mobile, Alabama) radar (gray line). Vertical dashed lines indicate where the inflection point of fitted curve lines occurs. Sun angle is $-6^{\circ}$ at the end of civil twilight. Data from Smolinsky et al. (2013) and Buler and Moore (2011) 
nautical twilight (sun angle between $-6^{\circ}$ and $-12^{\circ}$ ) (Cochran 1987; Mills et al. 2011). Additionally, mean peak radar departure in spring from Gauthreaux's (1971) study in coastal Louisiana, USA, was at $-9^{\circ}$, matching that of thrushes from Smolinsky et al. (2013). Admittedly, the data from this two-study comparison were from different seasons and years. This may highlight the possibility of annual variability in mean departure times. It also highlights the fact that individual species are known to vary in their departure timing; other species exhibit earlier departure than Swainson's thrush (Åkesson et al. 1996, 2001). It is also possible that other biota (e.g., insects) may contribute to the early exodus reflectivity around the end of civil twilight (Westbrook 2008).

\subsubsection{Displacement and Dispersion}

Dispersion of birds throughout the radar domain is evident over time and can affect the spatial accuracy and precision of the georeferenced data. Wintering waterfowl tend to disperse heterogeneously in multiple directions when initiating feeding flights. An effective correction for this spreading behavior of waterfowl during feeding flights is currently elusive. Estimates of median dispersal distances of birds from their ground sources over time closely match the optimal bandwidth for kernel smoothing of ground waterfowl densities and the scale at which radar data are spatially autocorrelated (Buler et al. 2012b). Consequently, dispersal leads to increased loss of spatial structure in reflectivity scans and to autocorrelation of reflectivity measures at greater distances. It also leads to a slight weakening of the association between waterfowl density aloft and observed waterfowl density on the ground. Despite autocorrelation in reflectivity measures out to about $4 \mathrm{~km}$ at the optimal sampling time, finer-scale associations of birds with their ground sources can still be discerned when summarizing data across multiple sampling nights, particularly where discrete patches of suitable habitat within an unsuitable habitat matrix are sampled by multiple radar sample volumes.

In contrast, migrating landbirds leave their stopover sites in a relatively uniform mean speed and direction, so adjusting for their displacement is possible although difficult to implement (Buler and Diehl 2009). Even after adjusting for displacement, the strength of associations between the reflectivity of birds aloft and the dominant habitats of their ground sources does not always improve, likely due to uncertainty in details of estimating the extent of displacement. However, adjusting for displacement may improve associations with coastal habitats and with small habitat patches or narrow, linear habitats like riparian corridors. This is because birds may take off from one habitat type and be detected above another. Associations of birds from habitat patches or sites that are smaller than the physical dimensions of a single radar sample volume are likely not possible due to mixing from birds emanating from other locations within the sample volume (Buler et al. 2012b). Moreover, determining terrestrial habitat associations at far ranges from the radar may be less reliable because the radar beam passes farther above the earth's surface, increasing the displacement of animals from their ground source in the time it takes for them to fly up into the beam (Diehl and Larkin 2005). This possibility served as a rationale for 
trimming data at far ranges for Ruth et al. (2012), yet remains to be empirically tested.

\subsubsection{Taxonomic Identification}

Identification of flying animals observed by WSR remains a key challenge, even for coarse taxonomic discrimination of birds from insects and bats. This is true for all radar studies of animals aloft, not just when mapping their terrestrial distributions. During spring and autumn migratory seasons, birds, insects, and bats likely overlap in their flight activity (Cryan 2003; Fleming and Eby 2003; Gauthreaux and Livingston 2006; Alerstam et al. 2011; Larkin and Diehl 2012). Thus, WSR sample volumes can contain multiple taxa since they are large enough to contain tens to thousands of individual animals. Accordingly, species discrimination on WSR is not absolute but focuses instead on determining the classes of animals that dominate the airspace within the radar domain. Insects are typically discriminated from vertebrates by their slower horizontal airspeeds (Larkin 1991). Radar measures of the radial velocity of animals during the peak of flight activity (typically about $3 \mathrm{~h}$ after sunset) are used to characterize dominant taxa aloft for a given sampling day (e.g., Gauthreaux and Belser 1998; Ruth et al. 2012; Buler and Dawson 2014).

\subsection{Ecological Insights}

\subsubsection{Understanding How Migrating Birds Contend with Crossing Ecological Barriers and Extreme Weather Events}

Long-distance, intercontinental migratory birds must negotiate ecological barriers during their biannual journeys, and movement in relation to the Gulf of Mexico (GOM) is a highly conspicuous feature of the Nearctic-Neotropical bird migration system. Habitats along the northern coast of the GOM provide the last possible stopover before migrants make a nonstop flight of greater than $1000 \mathrm{~km}$ in fall, and the first possible landfall for birds returning north in spring, so migrant-habitat relations are critical when birds negotiate this geographical barrier (e.g., Kerlinger and Moore 1989; Moore et al. 1990; Deppe et al. 2015).

Radar mapping of migratory stopover distributions of birds along the northern GOM has provided valuable insight into how birds negotiate ecological barriers. In particular, the broad scale of radar observations has helped to reveal the interplay between extrinsic factors (e.g., weather and energetic condition) and finer-scale intrinsic factors (e.g., food) on stopover habitat selection, which may be especially acute along large ecological barriers (Gauthreaux 1975; Gauthreaux and Belser 1999; Gauthreaux et al. 2005; Buler and Moore 2011; LaFleur et al. 2016).

The most extensive continuous-surface mapping effort of spring bird stopover densities to date spans the northern GOM from Texas to Florida within $100 \mathrm{~km}$ of the coastline and incorporates 4 years of radar data (LaFleur et al. 2016). Most of the spatial variability in bird density is related to longitude, proximity to the coast, and the amount of hardwood forest cover in the landscape. At the broadest scale, winds and weather over the GOM have likely shaped the evolution of migration 
routes in this region (Able 1972; Moore and Kerlinger 1989; Moore et al. 1990; Rappole and Ramos 1994; Gauthreaux et al. 2005; Kranstauber et al. 2015). Accordingly, LaFleur et al. (2016) found exceptionally high bird densities in western Louisiana consistent with the existence of a trans-Gulf route from Mexico's Yucatan Peninsula that was identified from radar analysis of flight activity (Gauthreaux et al. 2005) and observed bird movements from telemetry studies (Callo et al. 2013; Stanley et al. 2015). However, annual variability revealed that this region does not always support the highest densities of migrants. In some years, the eastern panhandle of Florida had the greatest densities of migrants, suggesting a largely overlooked eastern trans-Gulf route also consistent with telemetry studies (Fraser et al. 2013; Stanley et al. 2015) and the influence of winds in shaping broadscale distributions of migrants crossing the GOM (Gauthreaux et al. 2005; Russell 2005).

Trans-Gulf migrants typically overfly coastal marshes to stop over in forested landscapes (Gauthreaux 1971, 1975; Gauthreaux and Belser 1998) or stop in forested landscapes at the immediate coastline when wide coastal marshes are absent (Buler and Moore 2011). However, high migrant densities at the immediate coast at some longitudes regardless of land cover type (LaFleur et al. 2016) and weakening of the relationship between migrant density and forest cover closer to the coastline (Buler and Moore 2011) provide evidence that some migrants are limited in their ability to select among habitats of different quality or are forced to land at the first dry ground they encounter. These constraints are likely the result of physiological stress (Moore et al. 1990; Kuenzi and Moore 1991; Spengler et al. 1995) or adverse weather experienced while aloft (Lowery 1945; Gauthreaux 1971).

The GOM is also a region that experiences some of the most severe weather events in the form of hurricanes that often coincide with the autumn migration season of landbirds and can impact their stopover distributions. For example, Hurricane Katrina caused extensive damage to bottomland hardwood forests within the Lower Pearl River Basin (Chambers et al. 2007; Chapman et al. 2008; Wang and $\mathrm{Xu}$ 2009) that migrants preferentially use at high densities during stopover (Buler and Moore 2011). Barrow et al. (2007) compared maps of bird stopover density around a single radar immediately after the storm to composite maps from previous years near the path of the hurricane. They found migrating birds stopping over in the region for several weeks after Katrina's passage increased their use of less-disturbed, upland pine forests near the damaged bottomlands. About 5 weeks after the hurricane struck, much of the surviving forest canopy in the Pearl River bottomlands began to grow new foliage and migrant use of these forested wetlands mostly returned to pre-Katrina levels. Thus, radar observations can reveal the flexibility of migrating birds for responding to acute, short-term, and broad-scale disturbance to stopover habitats. This unique ability of networked radars is possible given the comprehensive, broad-scale extent of radar coverage and their constant surveillance operation. These radar data can improve our understanding of the effects of hurricane events on the population dynamics of migrating birds and a macrosystem-scale understanding of the potential scope and importance of 
eco-evolutionary processes in the face of climate change (sensu Heffernan et al. 2014).

\subsubsection{Identifying Important Stopover Areas and Habitat Use Patterns of Birds Along Their Migration Routes}

In an analysis of autumn stopover densities of migrants in the northeastern United States, Buler and Dawson (2014) summarized reflectivity measures for each sample volume from 16 WSR-88Ds across nights and years $(2008,2009)$ to estimate the seasonal mean and coefficient of variation of daily bird stopover density. Using these metrics, they classified areas with the highest mean and lowest variability in reflectivity as the most important bird stopover use areas within the sampling ranges of individual radars (locally) and across all radars (regionally). Locally important areas generally were associated with deciduous forests within landscapes dominated by developed or agricultural lands, or near the shores of major water bodies. These results are consistent with those of Bonter et al. (2009), who analyzed data collected during spring migration by six WSR-88Ds in the Great Lakes basin. Large regionally important stopover areas were located along the north shore of Long Island Sound (Connecticut, New York), on the Delmarva Peninsula (Delaware, Maryland), near Baltimore and Washington, DC (Maryland, Virginia), along the western edge of the Adirondack Mountains (New York), and within the Appalachian Mountains (southwestern Virginia, West Virginia) (Buler and Dawson 2014).

Concentrations of migrants near coastlines are consistently found where stopover distributions have been mapped with radar (Bonter et al. 2009; Buler and Moore 2011; Buler and Dawson 2014; LaFleur et al. 2016). However, the availability of high-quality stopover habitats for birds is at odds with rapid human population growth in coastal regions (Crossett et al. 2004; Buler and Moore 2011). Anthropogenic disturbances and habitat loss likely limit birds' use of coastal habitats and exacerbate other constraints on habitat use by migrants in coastal areas (Buler and Moore 2011). Thus, the conservation of coastal stopover sites is of high priority for protection of migratory bird populations (Mehlman et al. 2005).

Radar mapping studies have also revealed high-density use of forests in humandominated landscapes, particularly urban parks within large cities (Bonter et al. 2009; Buler and Dawson 2014). Migrant stopover use of human-dominated landscapes has also been documented by large-scale citizen-science survey efforts in the United States (La Sorte et al. 2014b). Urban forests can provide resources for migrants to refuel during their stopovers (Seewagen and Slayton 2008). Forest patches may be particularly sought after by migrants who find themselves in human-dominated landscapes; the strongest positive relationships between bird stopover density and forest cover occurred in areas, like cities, with low amounts of forest cover in the landscape (Buler and Dawson 2014). Moreover, bird density was positively related to the amount of human development in the landscape near large cities. Thus, large cities actually had relatively greater bird densities within them after accounting for the amount of forest cover and other factors shaping migrant distributions. This supports the hypothesis that migrating birds may 
actually be attracted to large urban areas at a landscape scale. A possible mechanism could be phototaxis of migrants to the artificial light glow of big cities (Gauthreaux and Belser 2006), which has also been cited as a possible explanation for altitudinal shifts in migrants during flight (Bowlin et al. 2015).

Ruth et al. (2012) analyzed data from seven WSR-88Ds spanning the USMexico border to examine stopover habitat use patterns of migratory birds moving through the arid southwestern United States. Migrating birds are known to use riparian habitats in the Southwest (Carlisle et al. 2009), but the intervening arid habitats have received little study. Ruth et al. (2012) documented relatively low migrant densities in arid scrub/shrub habitats across the region. However, the dominance of this habitat type suggests that, collectively, scrub/shrub supports a large number of migratory birds during stopover and that the importance of a given habitat is more than a function of density alone.

Although radar-based maps of important stopover areas do not characterize their intrinsic qualities or ecological function, they can focus conservation actions on areas and habitats where they likely will benefit the largest numbers of migrants, regardless of how or why birds use them, and ensure that a network of suitable stopover sites are protected along migration routes (Hutto 2000; Mehlman et al. 2005; Faaborg et al. 2010). As such, they can provide direct input to local or regional conservation plans.

\subsubsection{Assess Waterfowl Response to Wetland Habitat Management and Restoration}

Radar observations of waterfowl distributions at landscape and regional scales have had important implications for waterfowl conservation and management planning. Buler et al. (2012a) used 13 years of radar data to quantify wintering waterfowl response to restored wetlands in California's Central Valley by sampling birds at the onset of evening feeding flights. Two radars provided data for approximately $57 \%$ of the land area enrolled in the United States Department of Agriculture's (USDA) Wetland Reserve Program (WRP). They found that daytime (i.e., roosting) use of WRP wetlands by wintering waterfowl increased dramatically after wetland restoration and was sustained for up to 8 years post-restoration. Variability in the magnitude of waterfowl densities after restoration was greater with greater density of birds in the local area before restoration, lower amount of surrounding wetland habitat within a $1.5 \mathrm{~km}$ radius, greater increase in site soil wetness (i.e., flooding) after restoration, and closer proximity to flooded rice fields that serve as important feeding grounds. The study corroborated the understanding that the juxtaposition of diurnal roosts and nocturnal feeding habitats is critical to effectively conserve and manage landscapes for wintering waterfowl (Haig et al. 1998; Stafford et al. 2010).

In addition to providing evidence of the value of restored wetlands, Buler et al. (2012a) used WSR observations to document a long-term shift in habitat use by waterfowl. Within the Central Valley, diurnal use of flooded rice fields by waterfowl nearly tripled over time from 1995 to 2007 relative to use of natural wetland habitats. Waterfowl use of flooded rice fields relative to use of natural wetlands was 
also greater during wetter winters. This corroborated a long-term radio-telemetry study that found similar shifts in habitat use by waterfowl (Fleskes et al. 2005).

In response to the Deepwater Horizon oil spill in summer 2010, the USDA implemented the Migratory Bird Habitat Initiative (MBHI) to provide temporary wetland habitat via managed flooding of agricultural lands for migrating and wintering waterfowl, shorebirds, and other birds along the northern GOM. Sieges et al. (2014) used WSR observations to show that birds responded positively to MBHI management by exhibiting greater relative bird densities within sites relative to prior years when no management was implemented and also concurrently relative to non-flooded agricultural lands. Like waterfowl in California, the magnitude of bird densities in managed wetlands was related to the surrounding landscape context. WSR observations provided strong evidence that MBHI sites offered birds wetland habitat inland from coastal wetlands impacted by the oil spill.

\subsection{The Future}

We highlight many of the issues of mapping terrestrial distributions of animals with radar that continue to pose future challenges and opportunities for improving aeroecological studies. These issues are either subjects of ongoing research efforts or are of great importance for advancing quantification of animal distributions using radar. We are hopeful that improved data quality control and processing techniques will continue to unleash the full research potential of WSR to advance our understanding of aeroecology in the future.

The natural history of some insects presents the opportunity to map the distributions of insects initiating flights. Many migratory insects initiate migratory flights around dusk in well-synchronized flights similar to birds (Reynolds and Riley 1979; Riley and Reynolds 1979; Riley et al. 1983). In fact, insect activity is often a source of contamination for efforts to map migrating bird distributions. Some aquatic insects, like many short-lived adult mayflies, emerge in high concentrations from aquatic habitats in well-synchronized crepuscular flights (Brittain 1982), which are readily detected by WSR. For example, in 1999, emerging mayflies of the genus Hexagenia were observed with WSR along the shores of Lake Erie after a 30-year absence due to hypoxia resulting from cultural eutrophication (Masteller and Obert 2000). There is interest in monitoring mayfly distributions and population dynamics in the face of anthropogenic alterations of water quality and other habitat threats (e.g., Fremling 1973; Corkum 2010). However, despite the fact that emergence flights are very distinct in nature and finite in duration, we could find no studies that have developed techniques to map distributions of aquatic insect emergence flights or terrestrial insect migratory flights. Thus, future studies are needed that merge radar observations with traditional insect survey techniques to map and monitor population distribution and dynamics of insects.

Further study is needed to comprehensively describe broad-scale flight initiation timing patterns among and within radars and to determine the factors that explain variability in exodus timing such as geographic position, weather, or species 
composition (Åkesson et al. 2001). For example, the impact of cloud cover on flight initiation is not consistent. While Cochran et al. (1967) found that several North American thrush species depart later at night under cloudy skies, Gauthreaux (1971) and Hebrard (1971) did not find that cloud cover delayed exodus among the collection of all migrating landbirds.

Another important assumption that needs future consideration is whether the terrestrial distribution derived from the first cohort of animals to initiate nightly flights is representative of the broader population of animals of interest. Automated tracking networks have documented that the first-departing migrants tend to move long distances in the direction of their ultimate migratory destination, while laterdeparting individuals may engage in short-distance relocation flights, sometimes in directions away from their ultimate migratory destination and may be in poorer energetic condition (Mills et al. 2011; Taylor et al. 2011; Schmaljohann and NaefDaenzer 2011; Smolinsky et al. 2013). If first flyers are biased toward birds in good energetic condition prepared for making a long duration flight, they may bias the densities of birds emanating from high-quality habitats or along main flyways. Future field work can test this assumption, and improved telemetry technology should continue to provide new insights into the exact flight timing and behavior of individual animals (Bridge et al. 2011).

Flying animals reflect radio energy in extremely complex ways (Edwards and Houghton 1959; P. Chilson, unpub. data) that continue to challenge efforts to quantify migrant density using radar. No progress has been made in confirming the existence of or correcting for bias in reflectivity measures due to the aspect of animals (i.e., their shape and exposure with respect to the radar) when quantifying animal densities aloft since Diehl and Larkin (2005) first broached the subject. Considerably more research in this area is needed to better understand both the effects of aspect on radar reflectivity and the impact of this inherent uncertainty on quantification.

The expansion and integration of terrestrial distribution maps of migrating birds from WSR data with large-scale field mapping efforts from eBird data (Fink et al. 2010) may help link seasonal changes in stopover habitat distributions with known compositional changes in migratory bird taxa (La Sorte et al. 2014a, b). Such efforts to merge eBird and radar data have not yet been attempted in earnest but hold promise to disentangle the aggregate density information provided by radar. Broadscale efforts to integrate ground surveys of bird-use days with radar-derived estimates of emigrant densities could be a cost-effective approach to get an index of stopover duration across multiple sites (sensu O'Neal et al. 2012) and broaden our understanding of the stopover ecology of migrating birds.

\section{References}

Able KP (1972) Fall migration in coastal Louisiana and the evolution of migration patterns in the Gulf region. Wilson Bull 84:231-242 
Able KP (1989) Skylight polarization patterns and the orientation of migratory birds. J Exp Biol 141:241-256

Åkesson S, Alerstam T, Hedenström A (1996) Flight initiation of nocturnal passerine migrants in relation to celestial orientation conditions at twilight. J Avian Biol 27:95-102

Åkesson S, Walinder G, Karlsson L, Ehnbom S (2001) Reed warbler orientation: initiation of nocturnal migratory flights in relation to visibility of celestial cues at dusk. Anim Behav 61:181-189

Alerstam T (1993) Bird migration. Cambridge University Press, New York

Alerstam T, Chapman JW, Bäckman J, Smith AD, Karlsson H, Nilsson C, Reynolds DR, Klaassen RHG, Hill JK (2011) Convergent patterns of long-distance nocturnal migration in noctuid moths and passerine birds. Proc R Soc B Biol Sci 278:3074-3080

Baldassarre GA, Bolen EG (1984) Field-feeding ecology of waterfowl wintering on the southern high plains of Texas. J Wildl Manag 48:63-71

Barrow WCJ, Buler JJ, Couvillion B, Diehl RH, Faulkner S, Moore FR, Randall L (2007) Broadscale response of landbird migration to the immediate effects of hurricane Katrina. In: Farris GS, Smith GJ, Crane MP, Demas CR, Robbins LL, Lavoire DL (eds) Science and the storms the USGS response to the hurricanes of 2005. Circular 1306. U.S. Geological Survey, Reston, pp 131-136

Bech J, Codina B, Lorente J, Bebbington D (2003) The sensitivity of single polarization weather radar beam blockage correction to variability in the vertical refractivity gradient. J Atmos Ocean Technol 20:845-855

Beekman JH, Nolet BA, Klaassen M (2002) Skipping swans: fuelling rates and wind conditions determine differential use of migratory stopover sites of Bewick's Swans Cygnus bewickii. Ardea 90:437-460

Bellrose FC, Crompton RD (1970) Migrational behavior of mallards and black ducks as determined from banding. Ill Nat Hist Surv Bull 30(3):167-234

Bellrose FC, Paveglio F, Steffeck DW (1979) Waterfowl populations and the changing environment of the Illinois River valley. Ill Nat Hist Surv Bull 32(1):1-54

Bonter DN, Gauthreaux SA, Donovan TM (2009) Characteristics of important stopover locations for migrating birds: remote sensing with radar in the Great Lakes Basin. Conserv Biol 23:440-448

Bowlin MS, Enstrom DA, Murphy BJ, Plaza E, Jurich P, Cochran J (2015) Unexplained altitude changes in a migrating thrush: long-flight altitude data from radio-telemetry. Auk 132:808-816

Bridge ES, Thorup K, Bowlin MS, Chilson PB, Diehl RH, Fleron RW, Hartl P, Roland K, Kelly JF, Robinson WD, Wikelski M (2011) Technology on the move: recent and forthcoming innovations for tracking migratory birds. Bioscience 61:689-698

Bridge ES, Pletschet SM, Fagin T, Chilson PB, Horton KG, Broadfoot KR, Kelly JF (2016) Persistence and habitat associations of Purple Martin roosts quantified via weather surveillance radar. Landsc Ecol 31(1):43-53

Brigham RM, Grindal SD, Firman MC, Morissette JL (1997) The influence of structural clutter on activity patterns of insectivorous bats. Can J Zool 75:131-136

Brittain JE (1982) Biology of mayflies. Annu Rev Entomol 27:119-147

Buler JJ, Dawson DK (2014) Radar analysis of fall bird migration stopover sites in the northeastern U.S. Condor 116:357-370

Buler JJ, Diehl RH (2009) Quantifying bird density during migratory stopover using weather surveillance radar. IEEE Trans Geosci Remote Sens 47:2741-2751

Buler JJ, Moore FR (2011) Migrant-habitat relationships during stopover along an ecological barrier: extrinsic constraints and conservation implications. J Ornithol 152:S101-S112

Buler JJ, Barrow WC, Randall LA (2012a) Wintering waterfowl respond to wetlands reserve program lands in California's Central Valley. USDA NRCS CEAP Conservation Insight

Buler JJ, Randall LA, Fleskes JP, Barrow WC, Bogart T, Kluver D (2012b) Mapping wintering waterfowl distributions using weather surveillance radar. PLoS One 7:e41571 
Caccamise DF, Lyon LA, Fischl J (1983) Seasonal patterns in roosting flocks of starlings and common grackles. Condor 85:474-481

Callo PA, Morton ES, Stutchbury BJ (2013) Prolonged spring migration in the Red-eyed Vireo (Vireo olivaceus). Auk 130:240-246

Carlisle JD, Skagen SK, Kus BE, Riper CV III, Paxtons KL, Kelly JF (2009) Landbird migration in the American West: recent progress and future research directions. Condor 111:211-225

Chambers JQ, Fisher JI, Zeng H, Chapman EL, Baker DB, Hurtt GC (2007) Hurricane Katrina's carbon footprint on US Gulf coast forests. Science 318:1107-1107

Chapman EL, Chambers JQ, Ribbeck KF, Baker DB, Tobler MA, Zeng H, White DA (2008) Hurricane Katrina impacts on forest trees of Louisiana's Pearl River basin. For Ecol Manag 256:883-889

Chilson PB, Frick WF, Stepanian PM, Shipley JR, Kunz TH, Kelly JF (2012) Estimating animal densities in the aerosphere using weather radar: to $\mathrm{Z}$ or not to $\mathrm{Z}$ ? Ecosphere 3:art72

Cleveland CJ, Betke M, Federico P, Frank JD, Hallam TG, Horn J, López JD, McCracken GF, Medellín RA, Moreno-Valdez A, Sansone CG, Westbrook JK, Kunz TH (2006) Economic value of the pest control service provided by Brazilian free-tailed bats in south-central Texas. Front Ecol Environ 4:238-243

Cochran WW (1987) Orientation and other migratory behaviours of a Swainson's thrush followed for $1500 \mathrm{~km}$. Anim Behav 35:927-929

Cochran WW, Montgomery GG, Graber RR (1967) Migratory flights of Hylocichla thrushes in spring: a radiotelemetry study. Living Bird 6:213-225

Corkum LD (2010) Spatial-temporal patterns of recolonizing adult mayflies in Lake Erie after a major disturbance. J Great Lakes Res 36:338-344

Cox RR, Afton AD (1996) Evening flights of female northern pintails from a major roost site. Condor 98:810-819

Cronin TW, Warrant EJ, Greiner B (2006) Celestial polarization patterns during twilight. Appl Opt 45:5582-5589

Crossett KM, Culliton TJ, Wiley PC, Goodspeed TR (2004) Population trends along the coastal United States: 1980-2008. National Oceanic and Atmospheric Administration, Silver Spring, MD

Crum TD, Alberty RL, Burgess DW (1993) Recording, archiving, and using WSR-88D data. Bull Am Meteorol Soc 74:645-653

Cryan PM (2003) Seasonal distribution of migratory tree bats (Lasiurus and Lasionycteris) in North America. J Mammal 84:579-593

Deppe JL, Ward MP, Bolus RT, Diehl RH, Celis-Murillo A, Zenzal TJ, Moore FR, Benson TJ, Smolinsky JA, Schofield LN, Enstrom DA, Paxton EH, Bohrer G, Beveroth TA, Raim A, Obringer RL, Delaney D, Cochran WW (2015) Fat, weather, and date affect migratory songbirds' departure decisions, routes, and time it takes to cross the Gulf of Mexico. Proc Natl Acad Sci 112:E6331-E6338

Diehl RH, Larkin RP (2005) Introduction to the WSR-88D (NEXRAD) for ornithological research. In: Ralph CJ, Rich TD (eds) Bird conservation implementation and integration in the Americas: proceedings of the third international partners in flight conference. USDA Forest Service, General Technical Report PSW-GTR-191, pp 876-888

Dingle H, Drake VA (2007) What is migration? Bioscience 57:113-121

Dokter AM, Åkesson S, Beekhuis H, Bouten W, Buurma L, van Gasteren H, Holleman I (2013) Twilight ascents by common swifts, Apus apus, at dawn and dusk: acquisition of orientation cues? Anim Behav 85:545-552

Doviak RJ, Zrnic DS (1993) Doppler radar and weather observations. Academic, San Diego

Drake V, Gatehouse A (1996) Population trajectories through space and time: a holistic approach to insect migration. In: Floyd RB, Sheppard AW, De Barro PI (eds) Frontiers of population ecology. Collingwood, CSIRO, pp 399-408

Eastwood E (1967) Radar ornithology. Methuen, London 
Eastwood E, Isted GA, Rider GC (1962) Radar ring angels and the roosting behaviour of starlings. Proc R Soc Lond B Biol Sci 156:242-267

Edwards J, Houghton EW (1959) Radar echoing area polar diagrams of birds. Nature 184:1059-1059

Elder FC (1957) Some persistent ring echoes on high powered radar. In: Proceedings of the sixth weather radar conference. Cambridge, pp 281-286

Ely CR (1992) Time allocation by greater white-fronted geese: influence of diet, energy reserves and predation. Condor 94:857-870

Faaborg J, Holmes RT, Anders AD, Bildstein KL, Dugger KM, Gauthreaux SA, Heglund P, Hobson KA, Jahn AE, Johnson DH, Latta SC, Levey DJ, Marra PP, Merkord CL, Nol E, Rothstein SI, Sherry TW, Sillett TS, Thompson FR, Warnock N (2010) Recent advances in understanding migration systems of New World land birds. Ecol Monogr 80:3-48

Fink D, Hochachka WM, Zuckerberg B, Winkler DW, Shaby B, Munson MA, Hooker G, Riedewald M, Sheldon D, Kelling S (2010) Spatiotemporal exploratory models for broadscale survey data. Ecol Appl 20:2131-2147

Fleming TH, Eby P (2003) Ecology of bat migration. In: Kunz TH, Fenton MB (eds) Bat ecology. The University of Chicago Press, Chicago, pp 156-208

Fleskes JP, Yee JL, Casazza ML, Miller MR, Takekawa JY, Orthmeyer DL (2005) Waterfowl distribution, movements, and habitat use relative to recent habitat changes in the Central Valley of California: a cooperative project to investigate impacts of the Central Valley joint venture and changing agricultural practices on the ecology of wintering waterfowl. Final report. U.S. Geological Survey - Western Ecological Research Center, Dixon Field Station, Dixon, $\mathrm{CA}$

Fraser KC, Silverio C, Kramer P, Mickle N, Aeppli R, Stutchbury BJ (2013) A trans-hemispheric migratory songbird does not advance spring schedules or increase migration rate in response to record-setting temperatures at breeding sites. PLoS One 8:e64587

Fremling CR (1973) Factors influencing the distribution of burrowing mayflies along the Mississippi River. In: Proceedings of the first international conference on Ephemeroptera. EJ Brill, Leiden, pp 12-15

Frick WF, Stepanian PM, Kelly JF, Howard KW, Kuster CM, Kunz TH, Chilson PB (2012) Climate and weather impact timing of emergence of bats. PLoS One 7:e42737

Gagnon F, Ibarzabal J, Savard J-PL, Bélisle M, Vaillancourt P (2011) Autumnal patterns of nocturnal passerine migration in the St. Lawrence estuary region, Quebec, Canada: a weather radar study. Can J Zool 89:31-46

Gauthreaux SA (1971) A radar and direct visual study of passerine spring migration in southern Louisiana. Auk 88:343-365

Gauthreaux SA (1975) Coastal hiatus of spring trans-Gulf bird migration. A rationale for determining Louisiana's coastal zone: Baton Rouge, Louisiana State University, Center for Wetland Resources, Coastal Zone Management Series report no 1, pp 85-91

Gauthreaux SA (1980) The influences of long-term and short-term climatic changes on the dispersal and migration of organisms. In: Gauthereaux SA (ed) Animal migration, orientation, and navigation. Academic, New York, pp 103-174

Gauthreaux SA, Belser CG (1998) Displays of bird movements on the WSR-88D: patterns and quantification. Weather Forecast 13:453-464

Gauthreaux SA, Belser CG (1999) Bird migration in the region of the Gulf of Mexico. In: Adams NJ, Slotow RH (eds) Proceedings of the 22nd international ornithological congress. Birdlife South Africa, Durban, pp 1931-1947

Gauthreaux SA, Belser CG (2003) Radar ornithology and biological conservation. Auk 120:266-277

Gauthreaux SA, Belser CG (2006) Effects of artificial night lighting on migrating birds. In: Rich C, Longcore $\mathrm{T}$ (eds) Ecological consequences of artificial night lighting. Island Press, Washington, DC, pp 67-93 
Gauthreaux SA, Livingston JW (2006) Monitoring bird migration with a fixed-beam radar and a thermal-imaging camera. J Field Ornithol 77:319-328

Gauthreaux SA, Belser CG, Blaricom DV (2003) Using a network of WSR-88D weather surveillance radars to define patterns of bird migration at large spatial scales. In: Berthold $P$, Gwinner E, Sonnenschein E (eds) Avian migration. Springer, Berlin, pp 335-346

Gauthreaux SA, Michi JE, Belser CG (2005) The temporal and spatial structure of the atmosphere and its influence on bird migration strategies. In: Greenberg R, Marra PP (eds) Birds of two worlds. Smithsonian Institution, Washington, DC, pp 182-196

Haig SM, Mehlman DW, Oring LW (1998) Avian movements and wetland connectivity in landscape conservation. Conserv Biol 12:749-758

Harper WG (1959) Roosting movements of birds and migration departures from roosts as seen by radar. Ibis 101:201-208

Harper DGC (1982) Competitive foraging in mallards: "Ideal free" ducks. Anim Behav 30:575-584

Hassell MP, Southwood TRE (1978) Foraging strategies of insects. Annu Rev Ecol Syst 9:75-98

Hebrard JJ (1971) The nightly initiation of passerine migration in spring: a direct visual study. Ibis 113:8-18

Heffernan JB, Soranno PA, Angilletta MJ Jr, Buckley LB, Gruner DS, Keitt TH, Kellner JR, Kominoski JS, Rocha AV, Xiao J (2014) Macrosystems ecology: understanding ecological patterns and processes at continental scales. Front Ecol Environ 12:5-14

Helbig AJ (1990) Depolarization of natural skylight disrupts orientation of an avian nocturnal migrant. Experientia 46:755-758

Helbig AJ, Wiltschko W (1989) The skylight polarization patterns at dusk affect the orientation behavior of Blackcaps, Sylvia atricapilla. Naturwissenschaften 76:227-229

Hodgkison R, Balding ST, Zubaid A, Kunz TH (2004) Habitat structure, wing morphology, and the vertical stratification of Malaysian fruit bats (Megachiroptera: Pteropodidae). J Trop Ecol 20:667-673

Holleman I, Delobbe L, Zgonc A (2008) Update on the European weather radar network (OPERA). In: Proceedings of the 5th European conference on radar in meteorology and hydrology, Helsinki, 30 June-4 July 2008

Horn JW, Kunz TH (2008) Analyzing NEXRAD doppler radar images to assess nightly dispersal patterns and population trends in Brazilian free-tailed bats (Tadarida brasiliensis). Integr Comp Biol 48:24-39

Hutto RL (2000) On the importance of en route periods to the conservation of migratory landbirds. Stud Avian Biol 20:109-114

Janes SW (1985) Habitat selection in raptorial birds. In: Cody ML (ed) Habitat selection in birds. Academic, New York, pp 159-188

Jones G, Rydell J (1994) Foraging strategy and predation risk as factors influencing emergence time in echolocating bats. Philos Trans R Soc B Biol Sci 346:445-455

Kelly JF, Shipley JR, Chilson PB, Howard KW, Frick WF, Kunz TH (2012) Quantifying animal phenology in the aerosphere at a continental scale using NEXRAD weather radars. Ecosphere 3:art16

Kerlinger P, Moore F (1989) Atmospheric structure and avian migration. Curr Ornithol 6:109-142

Kranstauber B, Weinzierl R, Wikelski M, Safi K (2015) Global aerial flyways allow efficient travelling. Ecol Lett 18:1338-1345

Kucera PA, Krajewski WF, Young CB (2004) Radar beam occultation studies using GIS and DEM technology: an example study of Guam. J Atmos Ocean Technol 21:995-1006

Kuenzi AJ, Moore FR (1991) Stopover of Neotropical landbird migrants on East Ship Island following trans-Gulf migration. Condor 93:869-883

La Sorte FA, Fink D, Hochachka WM, Farnsworth A, Rodewald AD, Rosenberg KV, Sullivan BL, Winkler DW, Wood C, Kelling S (2014a) The role of atmospheric conditions in the seasonal dynamics of North American migration flyways. J Biogeogr 41:1685-1696 
La Sorte FA, Tingley MW, Hurlbert AH (2014b) The role of urban and agricultural areas during avian migration: an assessment of within-year temporal turnover. Glob Ecol Biogeogr 23:1225-1234

Lack D, Varley GC (1945) Detection of birds by radar. Nature 156:446-446

LaFleur JM, Buler JJ, Moore FR (2016) Geographic position and landscape composition explain regional patterns of migrating landbird distributions during spring stopover along the northern coast of the Gulf of Mexico. Landsc Ecol 31:1-13

Larkin RP (1991) Flight speeds observed with radar, a correction: slow "birds" are insects. Behav Ecol Sociobiol 29:221-224

Larkin RP (2006) Locating bird roosts with Doppler radar. In: Timm R, O'Brien J (eds) Proceedings of the 22nd vertebrate pest conference. University of California, Davis, pp 244-249

Larkin RP, Diehl RH (2012) Radar techniques for wildlife biology. In: Silvy NJ (ed) The wildlife techniques manual. Research, vol 1, 7th edn. Johns Hopkins University Press, Baltimore, pp 319-335

Laughlin AJ, Taylor CM, Bradley DW, Leclair D, Clark RC, Dawson RD, Dunn PO, Horn A, Leonard M, Sheldon DR (2013) Integrating information from geolocators, weather radar, and citizen science to uncover a key stopover area of an aerial insectivore. Auk 130:230-239

Laughlin AJ, Sheldon DR, Winkler DW, Taylor CM (2014) Behavioral drivers of communal roosting in a songbird: a combined theoretical and empirical approach. Behav Ecol 25:734-743

Laughlin AJ, Sheldon DR, Winkler DW, Taylor CM (2016) Quantifying non-breeding season occupancy patterns and the timing and drivers of autumn migration for a migratory songbird using Doppler radar. Ecography 39(10):1017-1024

Lee L, Helsel D (2005) Statistical analysis of water-quality data containing multiple detection limits: S-language software for regression on order statistics. Comput Geosci 31:1241-1248

Liechti F, Witvliet W, Weber R, Bachler E (2013) First evidence of a 200-day non-stop flight in a bird. Nat Commun 4:art2554

Ligda MG (1958) Radar observations of blackbird flights. Tex J Sci 10:255-265

Lowery GH (1945) Trans-Gulf migration of birds and the coastal hiatus. Wilson Bull 57:92-121

Masteller EC, Obert EC (2000) Excitement along the shores of Lake Erie - Hexagenia - Echoes from the past. Great Lakes Res Rev 5:25

McCracken GF, Westbrook JK (2002) Bat patrol. Natl Geogr 201:14-23

McLaren JD, Buler JJ, Schreckengost T, Smolinsky JA, Boone M, Dawson DK, Walters EL (2018) Artificial light confounds broad-scale habitat use by migrating birds. Ecol Lett (in press)

McLaren JD, Shamoun-Baranes J, Bouten W (2013) Stop early to travel fast: modelling riskaverse scheduling among nocturnally migrating birds. J Theor Biol 316:90-98

Mehlman DW, Mabey SE, Ewert DN, Duncan C, Abel B, Cimprich D, Sutter RD, Woodrey MS (2005) Conserving stopover sites for forest-dwelling migratory landbirds. Auk 122:1281-1290

Mills AM, Thurber BG, Mackenzie SA, Taylor PD (2011) Passerines use nocturnal flights for landscape-scale movements during migration stopover. Condor 113:597-607

Moore FR, Kerlinger P (1989) Atmospheric structure and avian migration. Curr Ornithol 6:109-142

Moore FR, Phillips JB (1988) Sunset, skylight polarization and the migratory orientation of yellow-rumped warblers, Dendroica coronata. Anim Behav 36:1770-1778

Moore FR, Kerlinger P, Simons TR (1990) Stopover on a Gulf Coast barrier island by spring transgulf migrants. Wilson Bull 102:487-500

Moore FR, Gauthreaux SA, Kerlinger P, Simons TR (1995) Habitat requirements during migration: important link in conservation. In: Martin TE, Finch DM (eds) Ecology and management of neotropical migratory birds. Oxford University Press, New York, pp 121-144

Muheim R (2011) Behavioural and physiological mechanisms of polarized light sensitivity in birds. Philos Trans R Soc Lond B Biol Sci 366:763-771

Muheim R, Åkesson S, Phillips J (2007) Magnetic compass of migratory Savannah sparrows is calibrated by skylight polarization at sunrise and sunset. J Ornithol 148:485-494 
O'Neal BJ, Stafford JD, Larkin RP (2010) Waterfowl on weather radar: applying ground-truth to classify and quantify bird movements. J Field Ornithol 81:71-82

O'Neal BJ, Stafford J, Larkin RP (2012) Stopover duration of fall-migrating dabbling ducks. J Wildl Manag 76:285-293

Randall LA, Diehl RH, Wilson BC, Barrow WC, Jeske CW (2011) Potential use of weather radar to study movements of wintering waterfowl. J Wildl Manag 75:1324-1329

Rappole JH, Ramos MA (1994) Factors affecting migratory bird routes over the Gulf of Mexico. Bird Conserv Int 4:251-262

Raveling DG, Crews WE, Klimstra WD (1972) Activity patterns of Canada geese during winter. Wilson Bull 84:278-295

Reynolds DR, Riley JR (1979) Radar observations of concentrations of insects above a river in Mali, West Africa. Ecol Entomol 4:161-174

Riley JR, Reynolds DR (1979) Radar-based studies of the migratory flight of grasshoppers in the middle Niger area of Mali. Proc R Soc Lond B Biol Sci 204:67-82

Riley JR, Reynolds DR, Farmery MJ (1983) Observations of the flight behaviour of the army worm moth, Spodoptera exempta, at an emergence site using radar and infra-red optical techniques. Ecol Entomol 8:395-418

Robinson SK, Holmes RT (1982) Foraging behavior of forest birds: the relationships among search tactics, diet, and habitat structure. Ecology 63:1918-1931

Russell RW (2005) Interactions between migrating birds and offshore oil and gas platforms in the northern Gulf of Mexico: final report. U.S. Department of the Interior, Minerals Management Service, Gulf of Mexico OCS Region, New Orleans

Russell KR, Gauthreaux SA (1998) Use of weather radar to characterize movements of roosting purple martins. Wildl Soc Bull 26:5-16

Russell KR, Gauthreaux SA Jr (1999) Spatial and temporal dynamics of a purple martin premigratory roost. Wilson Bull 111:354-362

Russell KR, Mizrahi DS, Gauthreaux SA (1998) Large-scale mapping of purple martin pre-migratory roosts using WSR-88D weather surveillance radar. J Field Ornithol 69:316-325

Ruth JM, Diehl RH, Felix RK Jr (2012) Migrating birds' use of stopover habitat in the Southwestern United States. Condor 114:698-710

Ruthi L (1994) Observation of bat emergence from Reed Bat Cave (HR-004) with the WSR-88D radar. Okla Undergr 17:54-56

Schmaljohann H, Naef-Daenzer B (2011) Body condition and wind support initiate the shift of migratory direction and timing of nocturnal departure in a songbird. J Anim Ecol 80:1115-1122

Seewagen CL, Slayton EJ (2008) Mass changes of migratory landbirds during stopovers in a New York City park. Wilson J Ornithol 120:296-303

Shamoun-Baranes J, Alves J, Bauer S, Dokter A, Huppop O, Koistinen J, Leijnse H, Liechti F, van Gasteren H, Chapman J (2014) Continental-scale radar monitoring of the aerial movements of animals. Mov Ecol 2:9

Sieges ML, Smolinsky JA, Baldwin MJ, Barrow WC, Randall LA, Buler JJ (2014) Assessment of bird response to the migratory bird habitat initiative using weather-surveillance radar. Southeast Nat 13:G36-G65

Smolinsky J, Diehl R, Radzio T, Delaney D, Moore F (2013) Factors influencing the movement biology of migrant songbirds confronted with an ecological barrier. Behav Ecol Sociobiol 67:2041-2051

Spengler TJ, Leberg PL, Barrow WC (1995) Comparison of condition indices in migratory passerines at a stopover site in coastal Louisiana. Condor 97:438-444

Stafford J, Horath M, Yetter A, Smith R, Hine C (2010) Historical and contemporary characteristics and waterfowl use of Illinois River valley wetlands. Wetlands 30:565-576

Stanley CQ, McKinnon EA, Fraser KC, Macpherson MP, Casbourn G, Friesen L, Marra PP, Studds C, Ryder TB, Diggs NE, Stutchbury BJM (2015) Connectivity of wood thrush breeding, wintering, and migration sites based on range-wide tracking. Conserv Biol 29:164-174 
Taylor PD, Mackenzie SA, Thurber BG, Calvert AM, Mills AM, McGuire LP, Guglielmo CG (2011) Landscape movements of migratory birds and bats reveal an expanded scale of stopover. PLoS One 6:e27054

Vandewoestijne S, Van Dyck H (2011) Flight morphology along a latitudinal gradient in a butterfly: do geographic clines differ between agricultural and woodland landscapes? Ecography 34:876-886

Wang F, Xu YJ (2009) Hurricane Katrina-induced forest damage in relation to ecological factors at landscape scale. Environ Monit Assess 156:491-507

Weber TP, Fransson T, Houston AI (1999) Should I stay or should I go? Testing optimality models of stopover decisions in migrating birds. Behav Ecol Sociobiol 46:280-286

Westbrook JK (2008) Noctuid migration in Texas within the nocturnal aeroecological boundary layer. Integr Comp Biol 48:99-106

Westbrook JK, Eyster RS, Wolf WW (2014) WSR-88D doppler radar detection of corn earworm moth migration. Int J Biometeorol 58:931-940

Williams TC, Ireland LC, Williams JM (1973) High altitude flights of the free-tailed bat, Tadarida brasiliensis, observed with radar. J Mammal 54:807-821

Wingo S, Knupp K (2014) Multi-platform observations characterizing the afternoon-to-evening transition of the planetary boundary layer in northern Alabama, USA. Bound-Layer Meteorol 155:29-53

Winkler DW (2006) Roosts and migrations of swallows. Hornero 21:85-97

Winkler H, Leisler B (1985) Morphological aspects of habitat selection in birds. In: Cody ML (ed) Habitat selection in birds. Academic, New York, pp 415-434 